\title{
2,3,7,8-Tetrachloodibenzo-p-dioxin affects the differentiation of CD4 helper T cell
}

Pang, Chengfang; Zhu, Conghui; Zhang, Yuanyuan; Ge, Ying; Li, Shujuan; Huo, Shouliang; Xu, Tuan; Stauber, Roland H.; Zhao, Bin

Published in:

Toxicology Letters

Link to article, DOI:

10.1016/j.toxlet.2019.04.015

Publication date:

2019

Document Version

Peer reviewed version

Link back to DTU Orbit

Citation (APA):

Pang, C., Zhu, C., Zhang, Y., Ge, Y., Li, S., Huo, S., Xu, T., Stauber, R. H., \& Zhao, B. (2019). 2,3,7,8-

Tetrachloodibenzo-p-dioxin affects the differentiation of CD4 helper T cell. Toxicology Letters, 311, 49-57. https://doi.org/10.1016/j.toxlet.2019.04.015

\section{General rights}

Copyright and moral rights for the publications made accessible in the public portal are retained by the authors and/or other copyright owners and it is a condition of accessing publications that users recognise and abide by the legal requirements associated with these rights.

- Users may download and print one copy of any publication from the public portal for the purpose of private study or research.

- You may not further distribute the material or use it for any profit-making activity or commercial gain

- You may freely distribute the URL identifying the publication in the public portal 


\section{Title: 2,3,7,8-tetrachloodibenzo-p-dioxin affects the differentiation of CD4 helper $\mathbf{T}$ cell}

Chengfang Pang ${ }^{1,2}$, Conghui Zhu ${ }^{1,3}$ Yuanyuan Zhang ${ }^{4}$, Ying Ge ${ }^{5,6}$, Shujuan $\mathrm{Li}^{3}$, Shouliang $\mathrm{Huo}^{7}$, Tuan $\mathrm{Xu}^{1}$, Roland H. Stauber ${ }^{8}$, Bin Zhao ${ }^{1,9 *}$

${ }^{1}$ State Key Laboratory of Environmental Chemistry and Ecotoxicology, Research Center for Eco-environmental Sciences, Chinese Academy of Sciences, Beijing, 100085, China

${ }^{2}$ Department of Environment Engineering, Technical University of Denmark, Kongens Lyngby, 2800, Denmark

${ }^{3}$ Chinese Academy of Inspection and Quarantine, Beijing, 100176, China

${ }^{4}$ Department of Endocrinology, Linyi People’s Hospital, Linyi, 276003, China

${ }^{5}$ The Finsen Laboratory, Rigshospitalet, Faculty of Health and Medical Sciences, University of Copenhagen, 2100, Denmark

${ }^{6}$ Biotech Research and Innovation Centre, University of Copenhagen, 2200, Denmark

${ }^{7}$ State Key Laboratory of Environmental Criteria and Risk Assessment, Chinese Research Academy of Environmental Sciences, Beijing, 100012, China

${ }^{8}$ Department of Nanobiomedicine/ENT, University Medical Center of Mainz, Langenbeckstrasse 1, 55101 Mainz, Germany

${ }^{9}$ University of Chinese Academy of Sciences, Beijing, 100049, China

*Corresponding author: Bin Zhao, State Key Laboratory of Environmental Chemistry and Ecotoxicology, Research Center for Eco-environmental Sciences, Chinese Academy of Sciences, Shuangqing Road, No.18. Beijing, 100085, China. Email: binzhao@ rcees.ac.cn. Tel: + 86-010-62842867.

Chengfang Pang and Conghui Zhu contributed equally to the study. 


\begin{abstract}
2,3,7,8-Tetrachlorodibenzo-p-dioxin (TCDD), the most toxic congener of dioxins, is a persistent and ubiquitous environmental contaminant. Although the immunotoxic effects of TCDD have been reported, the mechanisms underlying these effects are still unclear. In this study, we have determined the toxic effects of TCDD on thymocytes and splenic T cells with in vitro cell culture systems. Magnetically isolated mouse splenic Th cells, Treg cells and the mixed spleen lymphocytes (SLC) were cultured and treated with TCDD and the differentiation of CD4 Th cells was determined by flow cytometery. Our results showed that different concentrations of TCDD caused immunotoxic effects through different toxicological mechanisms in both the purified mouse splenic Th cells and the mixed SLC. The low dose exposure to TCDD triggered regulatory effects in the immune system, while the high dose TCDD exposure resulted in severe immune toxicity. Notably, a decline of Treg subset was observed, suggesting an imbalanced immune regulation by TCDD treatment, as well as a possible decrease of TCDD's indirect effects on bystander immune cells. Our CD4 Th subset co-culture experiments showed that TCDD-induced pathobiology depended on immune cell balance, suggesting that cytokine-induced microenvironments further modulated toxic effects associated with TCDD exposure.
\end{abstract}

Keywords: Dioxin; TCDD; helper T cell; cell differentiation; immune suppression; AhR. 
1

2

\section{Graphic Abstract:}

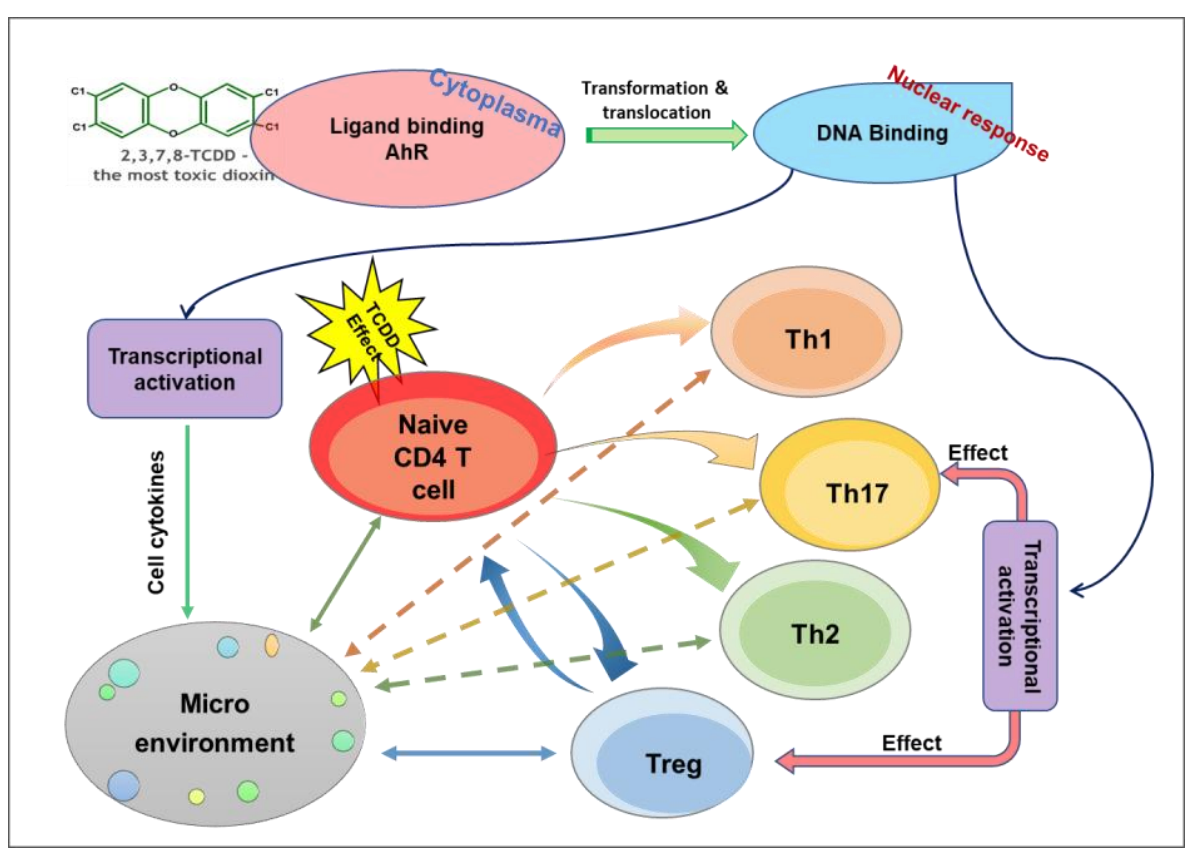




\section{Introduction}

2,3,7,8-tetrachloodibenzo-p-dioxin (TCDD), formed as an unintentional byproduct of organic synthesis and incomplete combustion, (Sorg, 2013) is the most potent compound among the polychlorinated dibenzo-p-dioxins. TCDD attracted widespread attention in the 1970's when it was discovered to be a contaminant in the herbicide, Agent Orange, and was shown to cause birth defects in rodents (York and Mick, 2008). It continues to be a concern because of its widespread distribution in the environment, persistence in the food chain, and toxicity. Previous studies showed that acute exposure to TCDD results in a variety of human health problems, including immune dysfunction (such as inflammatory autoimmune diseases), neurological pathologies, abnormal development, diabetes, and carcinogenesis (Hankinson, 2005; Luch, 2005).

TCDD can induce a variety of adverse biological and physiological reactions, including immunotoxicity in mammals, e.g., thymus atrophy and suppression of antibody production and cytotoxic $\mathrm{T}$ cells activation (Kerkvliet, 2002). The mechanisms through which TCDD alters the immune response and promotes immunotoxicity are still not well understood. Many studies have demonstrated that TCDD can impair the immune system, modulate the Th effector cells and other immune cells directly or indirectly through affecting the production of cytokines from the immune cells (Chighizola and Meroni, 2012; Quintana, 2013; Tomar and Kerkvliet, 1991). Singh et al. (2008) have shown that TCDD mediates toxicity through activation of the AhR (Singh et al., 2008). The AhR signaling pathway plays an important role in modulating the progression of inflammatory autoimmune diseases (Hao and Whitelaw, 2013; Podechard et al., 2008; Veldhoen et al., 2008), especially for Th cell-mediated inflammation (Esser et al., 2009a; Quintana et al., 2008).

The AhR gene has been shown to be highly conserved throughout evolution, which provides evidence of the fundamental importance of AhR in biological systems (Esser et al., 2009b; Veldhoen et al., 2008; Lin et al., 2001; Esser et al., 2009b; Quintana et al., 2008). In mice, for instance, targeted disruption of the AhR caused an incomplete development of immune organs and an altered immune function (Veldhoen et al., 2008; Lin et al., 2001). More recently, experimental and epidemiology studies have shown that the role of AhR in the immune system is particularly related to $\mathrm{CD} 4$ helper $\mathrm{T}$ cells $\left(\mathrm{CD} 4^{+} \mathrm{T}\right.$ cells $)$ mediated inflammation (Esser et al., 2009b; Quintana et al., 2008). However, whether AhR is essential 
for the development of a functional immune system is not known (Esser et al., 2009a,b; Quintana et al., 2008; Kerkvliet et al., 2002; Gogal et al., 2008).

$\mathrm{CD} 4^{+} \mathrm{T}$ cells play an integral role in adaptive immune responses. Activation of $\mathrm{CD} 4^{+} \mathrm{T}$ cells needs antigen recognition in the context of MHC- II molecules (expressed on so-called professional APC such as Macrophage and DC), and then the activated effector T helper cells produce functional cytokines. Following activation, naïve $\mathrm{CD}^{+} \mathrm{T}$ cells differentiate into one of several lineages of T helper cells (Th1, Th2, Th17, or Treg), depending primarily on the stimulation factors, the strength of the T Cell Receptor (TCR) signal, and the cytokines present in the surrounding extracellular environment. Differentiation of each T cell subset is associated with the expression of specific transcription factors, followed by the secretion of a defined array of cytokines that mediate response to the antigen. Failure to activate an appropriate $\mathrm{T}$ cell response can lead to chronic infection while exaggerated $\mathrm{T}$ cell responses can cause excessive tissue damage and are associated with inflammatory and autoimmune diseases. Th1 and Th17 are the two, major functional helper T cell subsets that play an important role in pro-inflammatory and inflammatory autoimmune diseases (Damsker et al., 2010; Solt et al., 2011 Xia et al., 2013).

Exposure to TCDD clearly impairs T cell-dependent immune responses, which contribute to promoting inflammatory autoimmune diseases (Gogal and Holladay, 2008; Holladay et al., 2011). However, it is still difficult to determine whether such immune effects are related to toxicity mediated by ligand-activated AhR signaling, or to its immune regulation. Among the subsets of T cells, both regulatory Th and effector cells (Th1, Th2, and Th17) can exert either beneficial or pathogenic effects depending on the particular biological settings (Zhu, et al., 2014). The importance of $\mathrm{CD} 4^{+} \mathrm{CD} 25^{+}$(Treg) in suppressing inflammation has become increasingly clear over the past several years (Josefowicz et al., 2012). Ligand activated AhR can regulate T-cell differentiation, specifically through activation of Treg cells and down-regulation of the pro-inflammatory Th17 cells (Hao and Whitelaw, 2013; Singh et al., 2011). To find how TCDD affected the immune system, especially the biological effects during the process of Th cells differentiation, we investigated the biological effects of TCDD on differentiation of Th cell subsets in vitro and the potential molecular mechanisms. This 
study contributes to the overall understanding of the molecular mechanisms of TCDD induced Th cells differentiation.

\section{Materials and methods}

\subsection{Animals}

Eight to ten-week-old male C57BL/6 mice were purchased from Vital River Laboratories. AhR knockout (Ko) (Chris Bradfield; on C57BL/6J background) mice were purchased from the Jackson Laboratory. All mice were housed in a $12 \mathrm{~h}$ light/dark cycle and temperature-controlled specific, pathogen-free conditions at the institute for animal experimentation. The AhR knockout mice were genotyped by PCR. All animal practices were carried out in accordance with the approved guidelines by the Institutional Animal Care and Use Committee (IACUC) of the Institute of Psychology, China Academy of Sciences, China.

\subsection{Antibodies and Other Reagents}

FITC-labeled anti-CD4 (BD Biosciences, \#555346, USA), PE-labeled anti CD25 (BD Bioscience, \#14-0251-85, USA), PE-labeled anti INF- $\gamma$ (eBioscience, \#12-1191-82, USA), PE-Cy7-labeled anti-IL4, Alexa 647 labeled anti-IL17 (BD Bioscience, \#560184, USA), Hrizon V450 labeled anti-FoxP3 (BD Bioscience, \#561293, USA), the staining buffer, and a transcription factor buffer set were purchased from BD Bioscience. Carboxyfluorescein diacetate succinimidyl ester (CFSE, \#65-0850, USA) was purchased from eBioscience. The detection of cytokines TGF- $\beta$ (eBioscience, \#BMS614-2, USA) from culture medium was measured by ELISA (eBioscience, USA). ELISA was performed using each specific Ab for the cytokine according to the manufacture's instruction. TCDD (Wellington Laboratories Inc., Canada) dissolved in DMSO (Amresco, USA) was used in the in vitro studies. For cell isolation, magnetic cell sorting methods were used and the corresponding isolation kits were purchased from StemCell Technologies (\#19722, \#18761, USA). Recombinant mouse rIL2 was purchased from PeproTech (\#212-12, Canada). Concanavalin A was purchased from Sigma-Aldrich (\#C0412, USA). A luminescent cell viability assay was used to evaluate the cytotoxicity, and the assay kit was purchased from Promega (\#G7571, USA).

\subsection{Preparation of spleen lymphocytes and target cell isolation}

The spleen was isolated from C57BL/6 mouse in sterile buffer (1×PBS with 2\% FBS and 1 $\mathrm{mM}$ EDTA, $\mathrm{Ca}^{+} / \mathrm{Mg}^{+}$free) and meshed properly. The cell suspension was filtered through a $70 \mu \mathrm{m}$ nylon cell strainer into a $50 \mathrm{~mL}$ conical tube and rinsed with up to $20 \mathrm{~mL}$ of the 
recommended medium. The cells were collected by centrifugation (1500 rpm, $10 \mathrm{~min})$ and re-suspend at $1-1.5 \times 10^{8}$ cells $/ \mathrm{mL}$ in the recommended medium. The obtained spleen single cell suspension was used for the Th cell Pre-Enrichment and CD25 positive selection, according to the manufacture's instruction (STEMCELL Technologies Inc, Canada). Cell survival evaluation was conducted using conventional trypan blue staining under an optical microscope, and the cell purity was determined by the flow cytometry (BD Calibur). Percoll cell separation media density gradient isolation method was used for the mixed spleen lymphocyte (SLC) isolation, according to the manufacture's protocol (GE Healthcare, \#17-0891-02, USA).

Luminescent cell viability assay based on ATP measurement was used to examine the association of the cytotoxicity of low dose-level TCDD (4 nm, $20 \mathrm{~nm}$, and $40 \mathrm{~nm}$ ) with differing exposure times (after $24 \mathrm{~h}, 48 \mathrm{~h}$ and $72 \mathrm{~h}$ culture).

\subsection{In vitro cell expansion and culture}

To evaluate the immunosuppressive function of Treg in vitro, the mouse spleen Treg cells were isolated using the magnetic selection system, and the negative fraction, the $\mathrm{CD} 4^{+} \mathrm{CD} 25^{-}$ cell (Tneg), was expanded and served as controls in the process. The isolated cells were placed in culture at $2 \times 10^{6}$ cell/1.4 mL/well (12 wells plate) in a modified RPMI1640 medium with $10 \% \mathrm{FBS}, 100 \mathrm{U} / \mathrm{mL}$ penicillin and streptomycin, $2 \mathrm{mM}$ glutamine, $50 \mu \mathrm{M}$ 2-Mercaptoethanol, $10 \mathrm{mM}$ HEPES, and $0.5 \mathrm{mM}$ sodium pyruvate. Anti-mouse CD3 and CD28 coated $4 \mu \mathrm{m}$ polystyrene dynabeads (Invitrogen, USA) at 2:1 or 1:1 ratio, and 2000 $\mathrm{U} / \mathrm{mL}$ or $30 \mathrm{U} / \mathrm{mL}$ of recombinant mouse IL-2 (PeproTech, USA) were added for Treg or CD4 Th cell culture in vitro, respectively. To monitor and evaluate the proliferation of target cells, the CFSE was used according to the manufacture's instruction (eBioscience, USA). Negatively isolated mouse splenic Tneg cells were cultured in modified RPMI1640 medium with $4 \mu \mathrm{g} / \mathrm{mL}$ Concanavalin A (Con A). After four days of coculture, cells were harvested and separated with the dynabeads on a magnet and subsequently analyzed for CFSE by flow cytometry.

\subsection{Flow Cytometry for identification of TCDD effects on the differentiation of CD4 helper $T$ cell}

Mouse spleen Th cells, the whole mixed spleen lymphocytes, and isolated mouse spleen Tneg cells were cultured with TCDD (T1: $20 \mathrm{nM}, \mathrm{T} 2: 200 \mathrm{nM}$ ), vehicle, or medium control in the presence of $4 \mu \mathrm{g} / \mathrm{mL}$ Con A, respectively. After 4 days, $\mathrm{T}$ cells were collected and washed 
first with PBS and then with staining buffer. Cell suspension was prepared containing 1 million cells per $150 \mu \mathrm{L}$ staining buffer and stained with specific surface marker fluorescent antibodies (e.g., antibody for CD3, CD4, CD25) that were added and incubated for 30 minutes at $2-8{ }^{\circ} \mathrm{C}$. Cells were washed one time with $2 \mathrm{ml}$ of staining buffer afterwards and then moved forward to the intracellular staining procedures. Cells were fixed and permeabilized with the transcription factor buffer set (BD Pharmingen, USA) at $2-8^{\circ} \mathrm{C}$ for 35 minutes, protected from light. Then the cells were washed two times with perm/wash buffer. After that, cells were intracellularly stained with anti-CD4, IFN- $\gamma$, IL17, IL4, and FoxP3 Abs, then measured by flow cytometry. FACS was performed with the Beckman Coulter (Gallios) system. Cells from each group were collected and counted at the end of the experiments.

To evaluate the AhR signaling pathway, spleen $\mathrm{CD}^{+} \mathrm{T}$ cells were isolated from AhR knockout or littermate control mice and stained with extracellular and intracellular antibodies, then evaluated by flow cytometry as discussed above.

\subsection{Reverse Transcriptase- PCR (RT-PCR)}

Total RNA was prepared by using the RNAqueous-Micro Kit (Life Technologies, \#AM1931, USA), and cDNA was synthesized using the Revert Aid First Strand cDNA Synthesis Kit (Thermo Scientific, \#K1622, USA), according to the manufacturer's instruction. mRNA expression was evaluated by relative quantitative PCR using SYBR Green I Master Mix (\#4707516001, Roche ,Germany) on a LightCycler 480 system (Roche, Germany), according to the manufacturer's instructions. Each assay was performed in triplicate using the cycling condition as follows: $95^{\circ} \mathrm{C}$ for $5 \mathrm{~min}$, followed by 45 cycles of $10 \mathrm{~s}$ at $95^{\circ} \mathrm{C}, 20 \mathrm{~s}$ at $60^{\circ} \mathrm{C}$ and $10 \mathrm{~s}$ at $72^{\circ} \mathrm{C}$. The level of target mRNA, including FoxP3, GATA3, T-bet, and ROR $\gamma$ t, were estimated using the typical $\mathrm{Ct}$ method $(2-\Delta \Delta \mathrm{Ct}$ method) by normalizing to GAPDH expression (LightCycler® 480 software, version 1.5, Roche, Germany). The following specific primers were used:

GAPDH forward 5'-CCTCGTCCCGTAGACAAAATG-3';

Reverse 5'-TCTCCACTTTGCCACTGCAA-3';

GATA3 primer 5'-AAGCTCAGTATCCGCTGACG-3';

Reverse 5'-GTTTCCGTAGTAGGACGGGAC-3';

T-bet forward 5'-AGCAAGGACGGCGAATGTT-3';

Reverse 5'-GTGGACATATAAGCGGTTCCC-3'; 
FoxP3 forward 5'-CCCATCCCCAGGAGTCTTG-3';

Reverse 5'-ACCATGACTAGGGGCACTGTA-3';

ROR $\gamma$ t- forward 5' - TCCTGCCACCTTGAGTATAGTC -3';

Reverse 5'- GTAAGTTGGCCGTCAGTGCTA -3'.

\subsection{Statistical analysis}

The flow cytometry data were analyzed with the FlowJo software (Tree Star, Inc.). A student's t-test with SPSS17 was used to analyze cell counts and cell viability, and the value was presented with mean with standard deviation. $P<0.05$ indicated a statistically significant difference.

\section{Results}

\subsection{The immunosuppressive function of Treg cells in vitro}

During the first attempt to expand the Treg cells in vitro, we took advantage of the magnetic selection system, and more than $80 \%$ of the isolated Treg cells were phenotypic $\mathrm{CD} 4{ }^{+} \mathrm{CD} 25^{+}$ cells, according to our flow cytometry analysis (Fig. 1A). In order to test the functions of these cells, we co-cultured Treg cells with Tneg $\left(\mathrm{CD} 4^{+} \mathrm{CD} 25^{-}\right)$cells for 4 days. The proliferation of Tneg cells was suppressed when mixed with Treg cells (Fig. 1B and C), indicating that the freshly isolated Treg cells were able to suppress the proliferation of the same allogeneic Tneg cells.
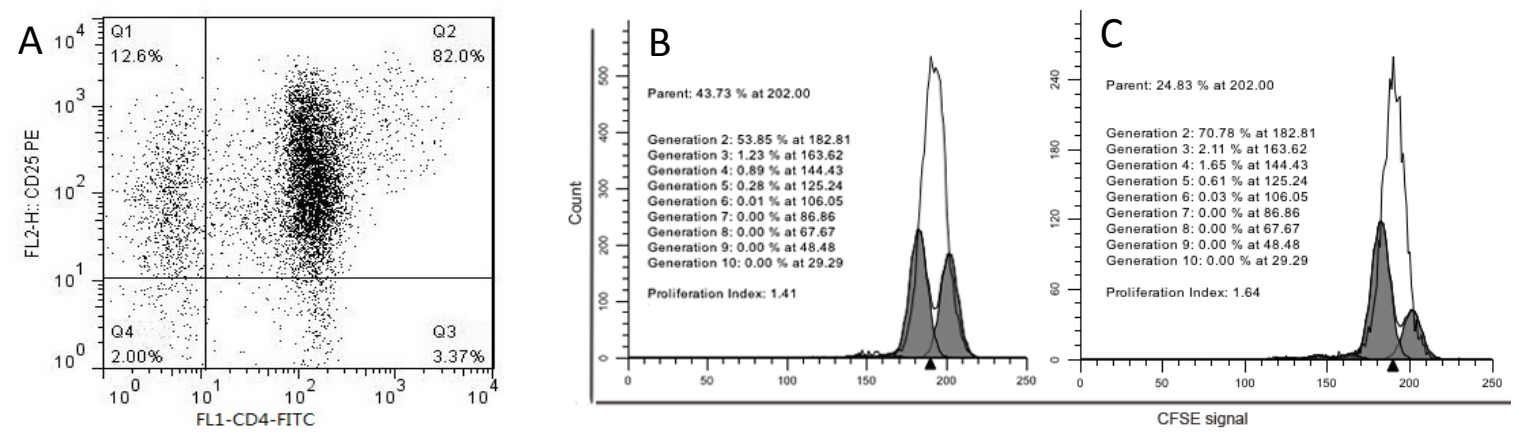

Fig. 1. The immunosuppressive function of Treg cell in vitro. A) Flow cytometry analysis of the purity of Treg in the isolated mouse spleen Treg using the magnetic selection system. B) CFSE labeled CD4 ${ }^{+}$ CD25 Tneg and freshly isolated Treg cells. The ratio of undivided parent cell was more than 43\%, which showed the potential suppression effect of Treg on Tneg proliferation. C) The proliferation rate of CFSE labeled CD4 $4^{+}$CD25 Tneg without Treg cells.

3.2 The immunomodulatory effects of TCDD on the differentiation of CD4 helper T cells (Th) 
The viability of CD4 helper T cells was not significantly different from the control group and TCDD treatment groups (at $4 \mathrm{nM}, 20 \mathrm{nM}$, and $40 \mathrm{nM}$ ); however, a decrease of cell viability was found as the time went on in both the lower concentration treatment and control groups (Fig. 2A). These results indicated that the primary CD4 T cell viability was impacted by the environment stimuli in the culture primary cells. To verify the hypothesis, we added $\mathrm{T}$ cell growth factors, e.g., IL-2 and Concanavalin A (ConA) in the RPMI1640, to further culture primary CD4 $\mathrm{T}$ cell for $72 \mathrm{~h}$. Our results showed that the viability of CD T cell was improved in the new cell culture medium (SI 2. Fig 2).

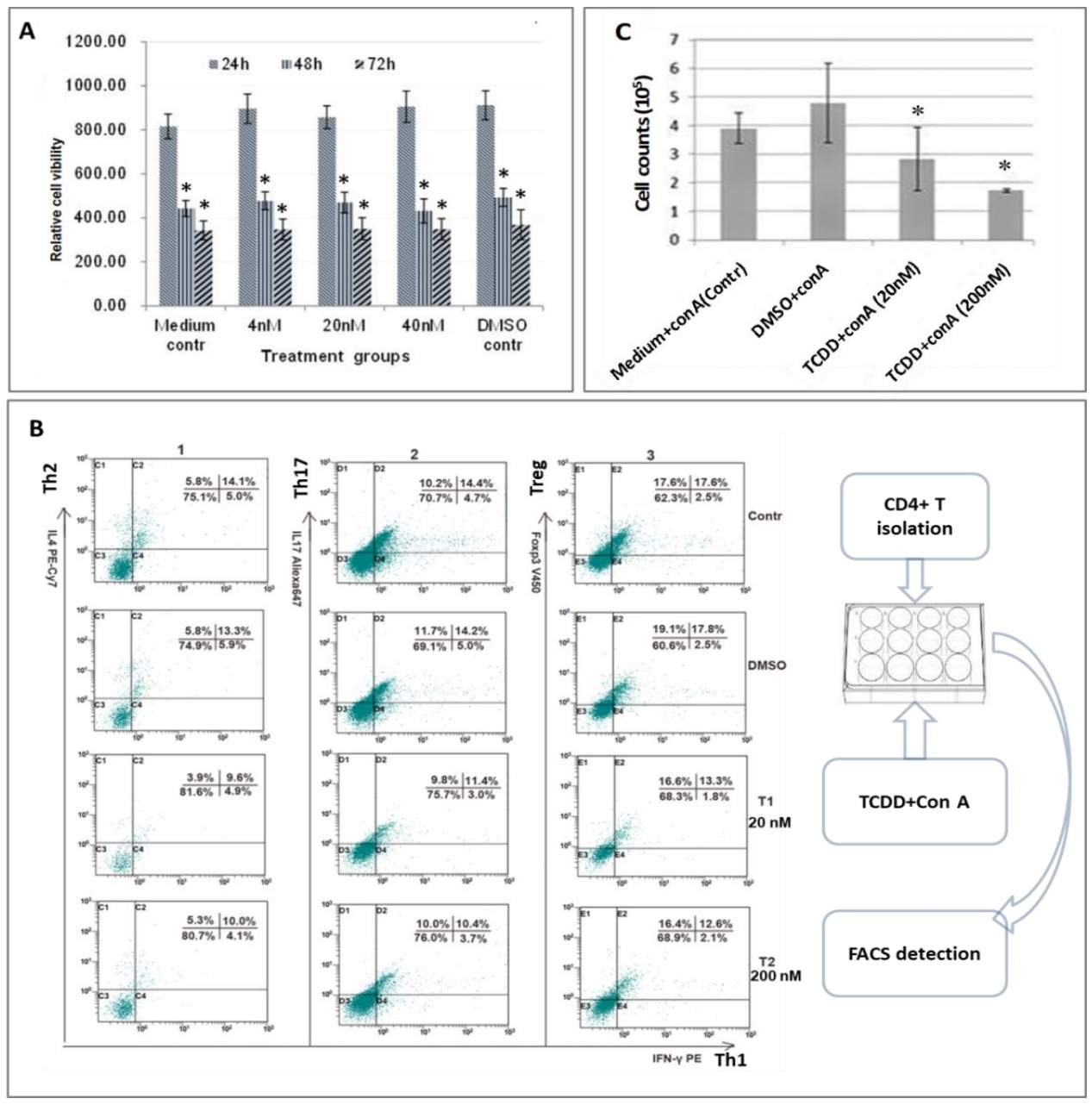

Fig. 2. The immunomodulatory effects of TCDD on the differentiation of CD4 helper T cell (Th). A) Cell viability of isolated mouse spleen Th cell exposed to TCDD after 3 days. There were no significant differences among groups initially, however, decreased cell viability was found in every group after 3 days of exposure. B) The effects of TCDD on the differentiation of Th were determined by multicolor flow cytometry after 4 days of exposure. Both the low dose exposure (20 nM) and the high dose exposure (200 nM) down regulated Th1 and Th17. The low dose exposure to TCDD (20 nM) had a significant immunosuppressive effect on the inflammatory effector Th cells. C) Cell counts from treatment and control groups at the end of the culture following treatment with different 
concentrations of TCDD.

The effects of TCDD on the differentiation of Th cells were determined by multicolor flow cytometry after 4 days of exposure. Both the low and high dose exposure ( $20 \mathrm{nM}$ and $200 \mathrm{nM}$, respectively) down-regulated the structure of the main inflammation effector Th cell subsets, especially Th1 and Th17 cells when compared to the DMSO and medium control. The results also showed that the low dose exposure to TCDD $(20 \mathrm{nM})$ had a significant immunosuppression effect on the differentiation of inflammatory effector Th cells. Though the high dose exposure of TCDD (200 nM) didn't further augment the down-regulation effect on these pro-inflammatory cells, a moderate decrease of Treg cell was observed after 4 days culture in vitro, compared with the T1 (20 nM) group (Fig. 2B, SI 3. Table 1).

Cell viability analysis also showed the cytotoxicity of TCDD and a dose-response relationship. As shown in Fig. 2C, the high level exposure of TCDD significantly decreased the survival of Th cells after 4 days of culture.

\subsection{The immunoregulatory effects of TCDD on the whole mixed spleen lymphocytes}

We further investigated the immune regulation effect of TCDD on the whole mixed spleen lymphocytes in SLC culture system. Our results showed that TCDD treatment inhibited the polarization of CD4 T cell toward the pro-inflammatory effector Th cell subsets after 4 days when compared to the medium control. At the same time, an apparent dose-response relationship between the TCDD exposure level and the immune suppression effect was found for all the effector Th cells except the Treg cell (Fig. 3A. SI 3. Table 2). There was no dose-response relationship between the total cell survival and the dose level of TCDD exposure (Fig. 3B). In addition, the expression of the characteristic transcription factors of Th1, Th2, and Th17 were not changed significantly after 4 days of TCDD exposure for both the low dose and high dose treatments when compared with the control (Fig. 3C). However, we found that the FoxP3 expression was increased over 10 times, which might suggest higher proliferation rate of Treg cell in the TCDD treatment groups (Fig. 3C). 

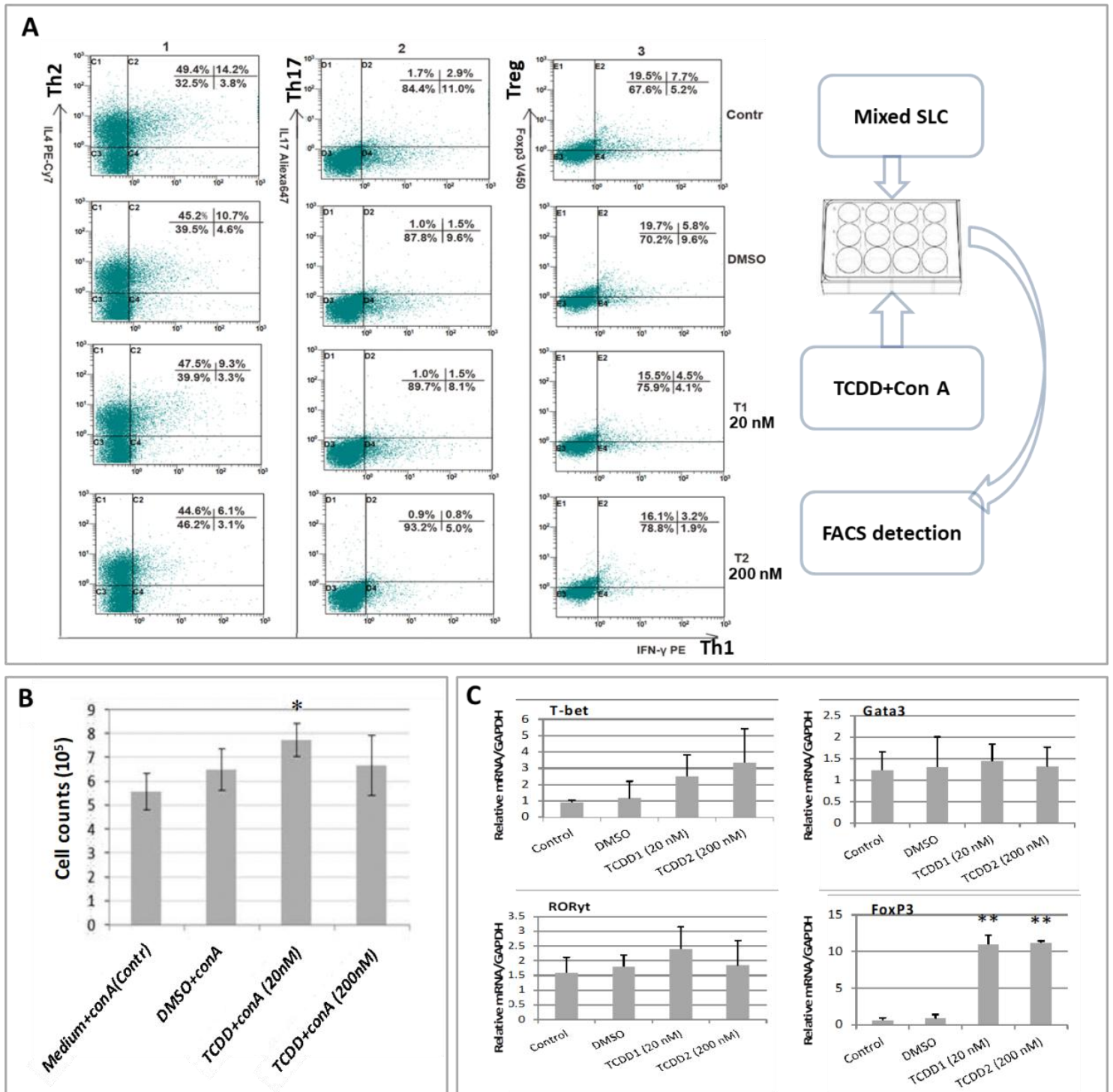

Fig. 3. The immunoregulatory effects of TCDD on the whole mixed spleen lymphocyte. A) The effects of TCDD on the differentiation of Th were determined by multicolor flow cytometry after 4 days exposure. Both the low dose TCDD (20 nM) and the high dose (200 nM) exposure decreased differentiation of Th cells in not only the inflammatory Th cell subsets (Th1, Th2, and Th17), but also the Treg cell. B) Cell counts from treatment and control groups at the end of the culture. There was no dose-response relationship between the total cell survival and the dose level of TCDD exposure. $C$ ) The expression of the characteristic transcription factors, T-bet for Th1, GATA3 for Th2, ROR $\gamma$ t for Th17, and FoxP3 for Treg, in the mixed SLC. The expression of the characteristic transcription factors of Th1, Th2, and Th17 were not changed significantly after 4 days TCDD exposure both for the low dose and high dose treatment group. The FoxP3 expression was increased over 10 times, which meant the increased proliferation of Treg cell in the TCDD treatment groups.

\subsection{TCDD-mediated immune modulation effects on the differentiation of Tneg cell}

A difference of polarization of CD4 T cell in the Tneg cell culture system was observed, as 
compared with our previous study of whole CD4 Th cells and mixed SLCs (Fig. 4A). The results showed that low dose exposure of TCDD (20 nM) significantly increased Th1 and Th2 polarization but slightly decreased Th17 polarization (Fig. 4A). The exposure to the high level of TCDD also significantly increased the Th1 cell proportion when compared to the control groups. However, compared to the low dose group, the differentiation of Th1 was decreased while both the Th2 and Th17 populations were slightly increased in high dose group when compared to that in the low dose group.

TCDD exposure exhibited a significant induction effect on TGF- $\beta$ production in the mixed SLC culture system, and there was also a dose-response effect (Fig. 4B). However, we didn't find such dose-response effect in the isolated $\mathrm{CD} 4^{+} \mathrm{T}$ lymphocytes. High dose exposure of TCDD (200 nM in the system) attenuated the increase of TGF- $\beta$ levels caused by low dose treatment in isolated CD4 ${ }^{+}$T lymphocytes (Fig. 4C).
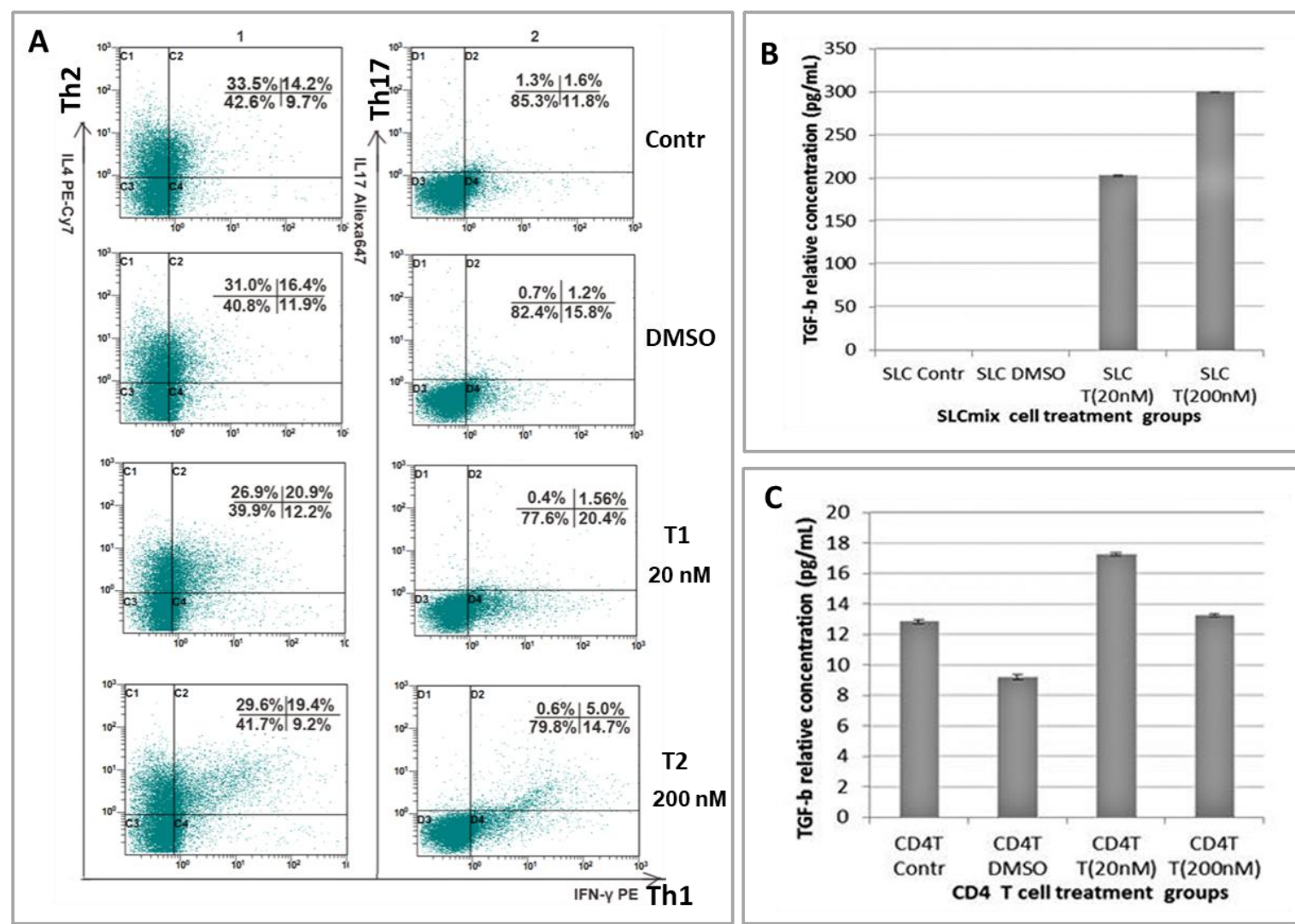

Fig. 4. TCDD-mediated immunomodulatory effects on the differentiation of Tneg cell. A) TCDD effects on the differentiation of Tneg cells. The low dose exposure of TCDD (20 nM) significantly increased differentiation of Th1 and Th2 but decreased Th17 slightly. High dose level of TCDD exposure significantly decreased the Th1 cell proportion and back to the control level, while slightly increased the Th2 and Th17. B) TGF- $\beta$ production in different treatment groups of mixed SLC. $\boldsymbol{C}$ ) TGF- $\beta$ production in different treatment groups of purified spleen CD4 Th cells. 
3.5 AhR signaling pathway might be involved in modulating the differentiation of $\mathrm{CD}^{+}$ helper $T$ cell subsets and required in the process of immune regulation induced by TCDD

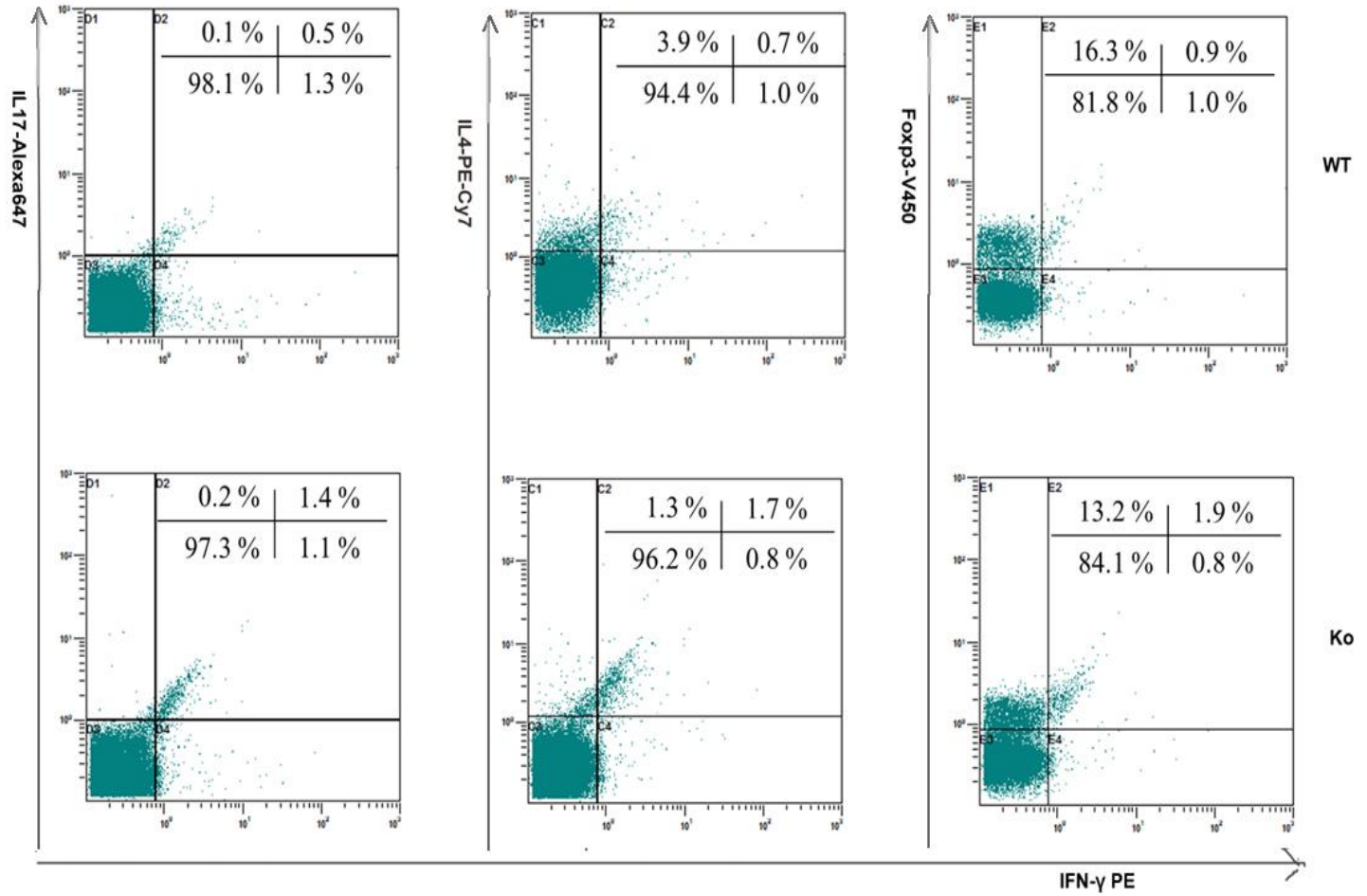

Fig. 5. Evaluation of AhR signaling pathway in modulating the differentiation of $\mathrm{CD}^{+}$helper $\mathrm{T}$ cell subsets and in the process of immune regulation induced by TCDD. The AhR knockout mice had a significant decrease in the proportion of Th2 cell among the spleen $C D 4^{+}$Th cells, while the proportion of Th17 and Th1 was slightly increased and decreased, respectively, when compared with the littermate wild type control (WT: wild type control, Ko: AhR knockout mice).

It has been shown that the activation of AhR is involved in the differentiation of Th17 cells, which plays an important role in natural immunogenicity (Nguyen et al., 2010; Quintana et al., 2008). Transgenic $A h R$-deficient mice and its littermate control (the $A h R^{+/+}$mice) were used for the $\mathrm{CD}^{+}{ }^{+}$Th cell isolation and detection of the constitutional differentiation in their subsets. The results of flow cytometry demonstrated that the $A h R$ knockout mice had a significant decrease in the proportion of Th2 cell among the spleen $\mathrm{CD}^{+}$Th cells, while the proportion of Th17 and Th1 was slightly increased and decreased, respectively, when compared with the littermate wild type control. We also found a significant decrease of constitutional differentiation of Treg cells in the AhR knockout mice treatment (Fig. 5. SI 3. Table 3). Thus, the absence or functional deletion of $A h R$ might significantly impair the differentiation of $\mathrm{CD}^{+}$helper T cells.

\section{Discussion}


Previous studies suggested that TCDD had a potential immune suppressive effect, which resulted in decreased inflammatory effector Th cells, and finally alleviated systemic lupus erythematous (SLE) progression (Li and McMurray, 2009). In our present study, we found that a low dose exposure of TCDD $(20 \mathrm{nM})$ contributed to a decrease in not only the inflammatory effector Th cells including the Th1, Th2, and Th17, but also the Treg cell. However, a high dose level of TCDD (200 nM) does not further affect these cells. On the contrary, high dose exposure of TCDD slightly increased their proportion, except for the Treg cell. Thus, our results suggest that the immunomodulatory effect of TCDD has a complex and non-linear dose-response relationship. A low dose TCDD contributes to the suppression of immune response, or promotes the immune tolerance to inflammatory autoimmune diseases that are caused by inflammatory effector Th cells. We also found that the high dose exposure of TCDD (200 nM) further decreases the FoxP3-expressing Treg cell when compared with the low dose $(20 \mathrm{nM})$ treatment. The results suggested that TCDD at high doses more likely targets Treg cell, accelerating the progression of inflammatory autoimmune diseases. Moreover, the high dose exposure of TCDD might increase the susceptibility to exogenous chemicals-induced inflammatory diseases in animals. The cell viability test analysis further confirmed that the cytotoxicity of TCDD might have a threshold which was not more than $200 \mathrm{nM}$.

The results of TCDD effects on the differentiation of $\mathrm{CD}^{+}$Th cell subsets in the whole mixed SLC culture system showed that both the low dose and the high dose of TCDD exposure decreased the proportion of $\mathrm{CD}^{+}{ }^{+} \mathrm{Th}$ cell, especially for the Th1 and Treg cells, which was similar to what we got in the purified $\mathrm{CD}^{+} \mathrm{T}$ cells system above. The gene expression of the characteristic transcription factors of each subset (T-bet for Th1, GATA for Th2, ROR $\gamma$ t for Th17, and FoxP3 for Treg cell) didn't show a significant decrease, except a significant increased expression of FoxP3, which usually suggested an activation of Treg. The gene expression results were not consistent with our immune-phenotyping results. The functional diversity depends on the development stage, the diversity of ligand type or structure, the cell or tissue types involved, the microenvironment of the study system, and the dose level of the test articles. Therefore, both the complex interactions mediated by multiple cytokines among the immune cells and the diversity of immune cell in such mixed culture system may contribute to the difference. Considering the important role of AhR signaling pathway in mediating TCDD biological effects, TCDD competition among immune cells within the microenvironment might be an influencing factor for the difference between the 
immune-phenotyping results and gene expression. Our results indicate the essential role of AhR for the development of a functional immune system is inconsistent with the activation or suppression of AhR leading to profound immunosuppression (Esser, 2009; Esser et al., 2009; Gogal and Holladay, 2008; Kerkvliet, 2012; Quintana et al., 2008; Quintana et al., 2010).

Our results show that the low dose TCDD exposure significantly increased the Th1, while decreaseing the proportion of Th2 and Th17 subsets. Inflammation or autoimmune diseases mediated by Th1 might be dominant in a circumstance of functional deletion of Treg cell. The relative high dose TCDD exposure, however, decreased the proportion of Th1, while increaseing the proportion of Th2 and Th17 cells. These results suggested a more frequent conversion among different cell subsets. Peripheral immune tolerance and homeostasis are dynamically maintained by functional differentiation within the FoxP3-expressing population, the occasional conversion between Treg and non-Treg cells, and the interactions among them. The absence of Treg cells contributed to a decrease in Th cells sensitivity to TCDD induced immune suppression effects. Treg cells play an important role not only in the immune regulation, but also in cytotoxicity processes induced by TCDD in a dose-dependent manner. TGF- $\beta$ has functions in the immunoregulation, proliferation, differentiation, and the development of Treg cell (Chen et al., 2003; Fantini et al., 2006). TCDD showed different impacts on the TGF- $\beta$ production in the two different test systems (the mixed SLC and the purified spleen CD4 Th cells). The TGF- $\beta$ content and the proportion of Treg cell were inconsistent in each respective test system. Further studies on the role of potent immune cytokines are necessary.

Our investigation of the structure of Th cell subsets of $A h R$-deficient mice demonstrated a difference from the wild type control. Moreover, considering the important role of AhR signaling in mediating the biological effects of dioxin-like materials (Benson and Shepherd, 2011; Kerkvliet, 2012; Quintana, 2013), we showed that the AhR signaling pathway played an important role in modulating the CD4 Th cell subsets constitutional differentiation. AhR might be required in the process of different immune modulation effect induced by TCDD. Previous in-vivo studies have showed that TCDD activated-AhR signaling pathways affect the immune response, especially that mediated by the CD4 Th cell subsets, through either inducing differentiation of functional Treg cells, while inhibiting the differentiation of Th17 cell at the same time (Quintana et al., 2008), or decreasing the proinflammatory cytokine levels (such as IL6, IL-12,IFN-r and TNF-a) and inducing the differentiation of Treg cell (Benson and Shepherd, 2011). These processes together contributed to suppressed 
experimental autoimmune diseases in a mouse model. The results showed that TCDD triggered the conversion of approximately $13 \%$ of the CD4 Th cells in culture CD4 Treg cells, which suggested a suppressive activity similar to that of Treg cells induced in vitro with TGF- $\beta$ or natural CD4 Treg cells isolated from mice (Quintana et al., 2008). These findings provided a new insight into immune effects and potential mechanisms involved with dioxin-like materials.

\section{Conclusions}

Our study provides evidence that TCDD affects CD4 Th cell-mediated immune homeostasis with strong dependency on dose and microenvironment. Exposure to the low doses of TCDD contributes to decreased proportions of inflammatory effector Th cells, while the high dose exposure lead to decreased proportions of Treg cells, which may promote an aberrant immune response. The absence of Treg cells decreases the immune regulation effects but increases the immune toxicity effects. Moreover, our study suggests that TCDD affects Th cell subsets differentiation and maturation processes in purified splenic CD4 cells as well as in mixed SLC. Our findings contribute to the understanding of how TCDD impacts immune modulation and immune toxicity, which is the key for the development and clinical application of therapeutic agents.

\section{Conflict of interest}

The authors declare no conflict of interest.

\section{Acknowledgements}

This work was supported in parts by the National Natural Science Foundation of China (grant number 21277168, 21525730, 21836004), the Strategic Priority Research Program of the Chinese Academy of Sciences (No. XDB14030401, XDB14030402), the Sanming Project of Medicine in Shenzhen (SZSM201811070), the National Natural Science Foundation of China Award (Grant No. 21407162. 2014), and the European Union's Seventh Framework Programme and Horizon 2020 Research and Innovation Programme under Marie Sklodowska-Curie Actions grant no. 713683 (H2020) (The H.C. Ørsted Postdoc programme, co-funded by Marie Skłodowska-Curie Actions). The authors would like to thank Kevin M. Guo at HGG Research LLC for editing this manuscript.

\section{References}

Benson, J.M., Shepherd, D.M., 2011. Aryl Hydrocarbon Receptor Activation by TCDD Reduces Inflammation Associated with Crohn's Disease. Toxicol Sci 120, 68-78.

Chen, W., Jin, W., Hardegen, N., Lei, K.J., Li, L., Marinos, N., McGrady, G., Wahl, S.M., 2003. 
Conversion of peripheral CD4+CD25- naive $\mathrm{T}$ cells to CD4+CD25+ regulatory $\mathrm{T}$ cells by TGF- $\beta$ eta induction of transcription factor FoxP3. J Exp Med 198, 1875-1886.

Chighizola, C., Meroni, P.L., 2012., The role of environmental estrogens and autoimmunity. Autoimmun Rev 11, A493-A501.

Damsker, J. M., Hansen, A. M., Caspi, R. R., 2010. Th1 and Th17 cells Adversaries and collaborators. Ann Ny Acad Sci 1183, 211-221.

Esser, C., 2009a. The immune phenotype of AhR null mouse mutants: Not a simple mirror of xenobiotic receptor over-activation. Biochem Pharmacol 77, 597-607.

Esser, C., Rannug, A., Stockinger, B., 2009b. The aryl hydrocarbon receptor in immunity. Trends Immunol 30, 447-454.

Fantini, M.C., Becker, C., Tubbe, I., Nikolaev, A., Lehr, H.A., Galle, P., Neurath, M.F., 2006. Transforming growth factor beta induced FoxP3+ regulatory $\mathrm{T}$ cells suppress Th1 mediated experimental colitis. Gut 55, 671-680.

Godfrey, W.R., Ge, Y.G., Spoden, D.J., Levine, B.L., June, C.H., Blazar, B.R., Porter, S.B., 2004. In vitro-expanded human CD4(+)CD25(+) T-regulatory cells can markedly inhibit allogeneic dendritic cell-stimulated MLR cultures. Blood 104, 453-461.

Gogal, R.M., Jr., Holladay, S.D., 2008. Perinatal TCDD exposure and the adult onset of autoimmune disease. J Immunotoxicol 5, 413-418.

Hankinson, O., 2005. Role of coactivators in transcriptional activation by the aryl hydrocarbon receptor. Arch Biochem and Biophys 433, 379-386.

Hao, N., Whitelaw, M.L., 2013. The emerging roles of AhR in physiology and immunity. Biochem Pharmacol 86, 561-570.

Holladay, S.D., Mustafa, A., Gogal, R.M., Jr., 2011. Prenatal TCDD in mice increases adult autoimmunity. Reprod Toxicol 31, 312-318.

Josefowicz, S.Z., Lu, L.F., Rudensky, A.Y., 2012. Regulatory T Cells: Mechanisms of Differentiation and Function. Annu Rev Immunol 30, 531-564.

Kerkvliet, N.I., 2002. Recent advances in understanding the mechanisms of TCDD immunotoxicity. Int Immunopharmacol 2, 277-291.

Kerkvliet, N.I., 2012. TCDD: an environmental immunotoxicant reveals a novel pathway of immunoregulation--a 30-year odyssey. Toxicol Pathol 40, 138-142.

Li, J., McMurray, R.W., 2009. Effects of chronic exposure to DDT and TCDD on disease activity in murine systemic lupus erythematosus. Lupus 18, 941-949.

Lin, T. M., Ko, K., Moore, R. W., Buchanan, D. L., Cooke, P. S., Peterson, R. E., 2001. Role of the aryl hydrocarbon receptor in the development of control and 2,3,7,8-tetrachlorodibenzo-p-dioxin-exposed male mice. J Toxicol Env Heal A 64, (4), 327-342.

Luch, A., 2005. Chemicals as tumor-inducing agents. Discov Med 5, 472-477.

Nguyen, N.T., Kimura, A., Nakahama, T., Chinen, I., Masuda, K., Nohara, K., Fujii-Kuriyama, Y., Kishimoto, T., 2010. Aryl hydrocarbon receptor negatively regulates dendritic cell immunogenicity 
via a kynurenine-dependent mechanism. Proc Nati Acad Sci USA 107, 19961-19966.

Podechard, N., Lecureur, V., Le Ferrec, E., Guenon, I., Sparfel, L., Gilot, D., Gordon, J.R., Lagente, V., Fardel, O., 2008. Interleukin-8 induction by the environmental contaminant benzo(a)pyrene is aryl hydrocarbon receptor-dependent and leads to lung inflammation. Toxicol Let 177, 130-137.

Quintana, F.J., 2013. The aryl hydrocarbon receptor: a molecular pathway for the environmental control of the immune response. Immunology 138, 183-189.

Quintana, F.J., Basso, A.S., Iglesias, A.H., Korn, T., Farez, M.F., Bettelli, E., Caccamo, M., Oukka, M., Weiner, H.L., 2008. Control of T-reg and TH17 cell differentiation by the aryl hydrocarbon receptor. Nature 453, 65 .

Quintana, F.J., Murugaiyan, G., Farez, M.F., Mitsdoerffer, M., Tukpah, A.M., Burns, E.J., Weiner, H.L., 2010. An endogenous aryl hydrocarbon receptor ligand acts on dendritic cells and $\mathrm{T}$ cells to suppress experimental autoimmune encephalomyelitis. Proc Nati Acad Sci USA 107, 20768-20773.

Quintana, F.J., Sherr, D.H., 2013. Aryl hydrocarbon receptor control of adaptive immunity. Pharmacol Rev 65, 1148-1161.

Singh, N.P., Nagarkatti, M., Nagarkatti, P., 2008. Primary peripheral T cells become susceptible to 2,3,7,8-tetrachlorodibenzo-p-dioxin-mediated apoptosis in vitro upon activation and in the presence of dendritic cells. Mol Pharmacol 73, 1722-1735.

Singh, N.P., Singh, U.P., Singh, B., Price, R.L., Nagarkatti, M., Nagarkatti, P.S., 2011. Activation of Aryl Hydrocarbon Receptor (AhR) Leads to Reciprocal Epigenetic Regulation of FoxP3 and IL-17 Expression and Amelioration of Experimental Colitis. Plos One 6.

Sorg, O., 2013. AhR signalling and dioxin toxicity. Toxicol Lett 230(2)

Solt, L. A., Kumar, N., Nuhant, P., Wang, Y. J., Lauer, J. L., Liu, J., Istrate, M. A., Kamenecka, T. M., Roush, W. R., Vidovic, D., Schurer, S. C., Xu, J. H., Wagoner, G., Drew, P. D., Griffin, P. R., Burris, T. P., 2011. Suppression of $\mathrm{T}(\mathrm{H}) 17$ differentiation and autoimmunity by a synthetic ROR ligand. Nature 472, (7344), 491-U547.

Sun, Y.V., Boverhof, D.R., Burgoon, L.D., Fielden, M.R., Zacharewski, T.R., 2004. Comparative analysis of dioxin response elements in human, mouse and rat genomic sequences. Nucleic Acids Res $32,4512-4523$.

Tomar, R.S., Kerkvliet, N.I., 1991. Reduced T-helper cell function in mice exposed to 2, 3, 7, 8-tetrachlorodibenzo-p-dioxin(TCDD). Toxicol Let 57, 55-64.

Veldhoen, M., Hirota, K., Westendorf, A.M., Buer, J., Dumoutier, L., Renauld, J.C., Stockinger, B., 2008. The aryl hydrocarbon receptor links $\mathrm{T}(\mathrm{H}) 17$-cell-mediated autoimmunity to environmental toxins. Nature 453, 106.

Xia, M., Liu, J.; Wu, X., Liu, S., Li, G., Han, C., Song, L., Li, Z.; Wang, Q., Wang, J., Xu, T., Cao, X., 2013. Histone methyltransferase Ash11 suppresses interleukin-6 production and inflammatory autoimmune diseases by inducing the ubiquitin-editing enzyme A20. Immunity 39, (3), 470-81.

York, G., Mick, H., 2008. Last Ghost of the Vietnam War. The Globe and Mail. Toronto, ON Canada: Phillip Crawley.

Zhu, C., Xie, Q., Zhao, B., 2014. The Role of AhR in Autoimmune Regulation and Its Potential as a 
Therapeutic Target against CD4 T Cell Mediated Inflammatory Disorder. Int J Mol Sci 15, 10116-10135. 


\section{Title: 2,3,7,8-tetrachloodibenzo-p-dioxin affects the differentiation of CD4 helper $\mathbf{T}$ cell}

Chengfang Pang ${ }^{1,2}$, Conghui Zhu ${ }^{1,3}$ Yuanyuan Zhang ${ }^{4}$, Ying Ge ${ }^{5,6}$, Shujuan $\mathrm{Li}^{3}$, Shouliang $\mathrm{Huo}^{7}$, Tuan $\mathrm{Xu}^{1}$, Roland H. Stauber ${ }^{8}$, Bin Zhao ${ }^{1,9 *}$

${ }^{1}$ State Key Laboratory of Environmental Chemistry and Ecotoxicology, Research Center for Eco-environmental Sciences, Chinese Academy of Sciences, Beijing, 100085, China

${ }^{2}$ Department of Environment Engineering, Technical University of Denmark, Kongens Lyngby, 2800, Denmark

${ }^{3}$ Chinese Academy of Inspection and Quarantine, Beijing, 100176, China

${ }^{4}$ Department of Endocrinology, Linyi People’s Hospital, Linyi, 276003, China

${ }^{5}$ The Finsen Laboratory, Rigshospitalet, Faculty of Health and Medical Sciences, University of Copenhagen, 2100, Denmark

${ }^{6}$ Biotech Research and Innovation Centre, University of Copenhagen, 2200, Denmark

${ }^{7}$ State Key Laboratory of Environmental Criteria and Risk Assessment, Chinese Research Academy of Environmental Sciences, Beijing, 100012, China

${ }^{8}$ Department of Nanobiomedicine/ENT, University Medical Center of Mainz, Langenbeckstrasse 1, 55101 Mainz, Germany

${ }^{9}$ University of Chinese Academy of Sciences, Beijing, 100049, China

*Corresponding author: Bin Zhao, State Key Laboratory of Environmental Chemistry and Ecotoxicology, Research Center for Eco-environmental Sciences, Chinese Academy of Sciences, Shuangqing Road, No.18. Beijing, 100085, China. Email: binzhao@ rcees.ac.cn. Tel: + 86-010-62842867.

Chengfang Pang and Conghui Zhu contributed equally to the study. 


\begin{abstract}
2,3,7,8-Tetrachlorodibenzo-p-dioxin (TCDD), the most toxic congener of dioxins, is a persistent and ubiquitous environmental contaminant. Although the immunotoxic effects of TCDD have been reported, the mechanisms behind-underlying these effects are still unclear. In this study, we have determined the toxic effects of TCDD on thymocytes and splenic T cells with in vitro cell culture systems. Magnetically isolated mouse splenic Th cells, Treg cells and the mixed spleen lymphocytes (SLC) were cultured and treated with TCDD and the differentiation of CD4 Th cells was determined by flow cytometery. Our results showed that different doses concentrations of TCDD caused immunotoxic effects through different toxicity-toxicological mechanisms in both the purified mouse splenic Th cells and the mixed SLC. The low dose exposure to TCDD triggered regulatory effects in the immune system, while the high dose TCDD exposure TCDD-resulted in severe immune toxicity. Notably, a decline of Treg subset was observed, suggesting an an imbalance inimbalanced immune regulation by TCDD treatment, as well as a possible decrease of indirect effects of $T C D D$ 's indirect effects on bystander immune cells. Our CD4 Th subset co-culture experiments showed that TCDD-TCDD-induced pathobiology depended on immune cell balance, suggesting that cytokine-induced microenvironments further modulated toxic effects associated with TCDD exposure.
\end{abstract}

Keywords: Dioxin; TCDD; helper T cell; cell differentiation; immune suppression; AhR. 


\section{Graphic Abstract:}

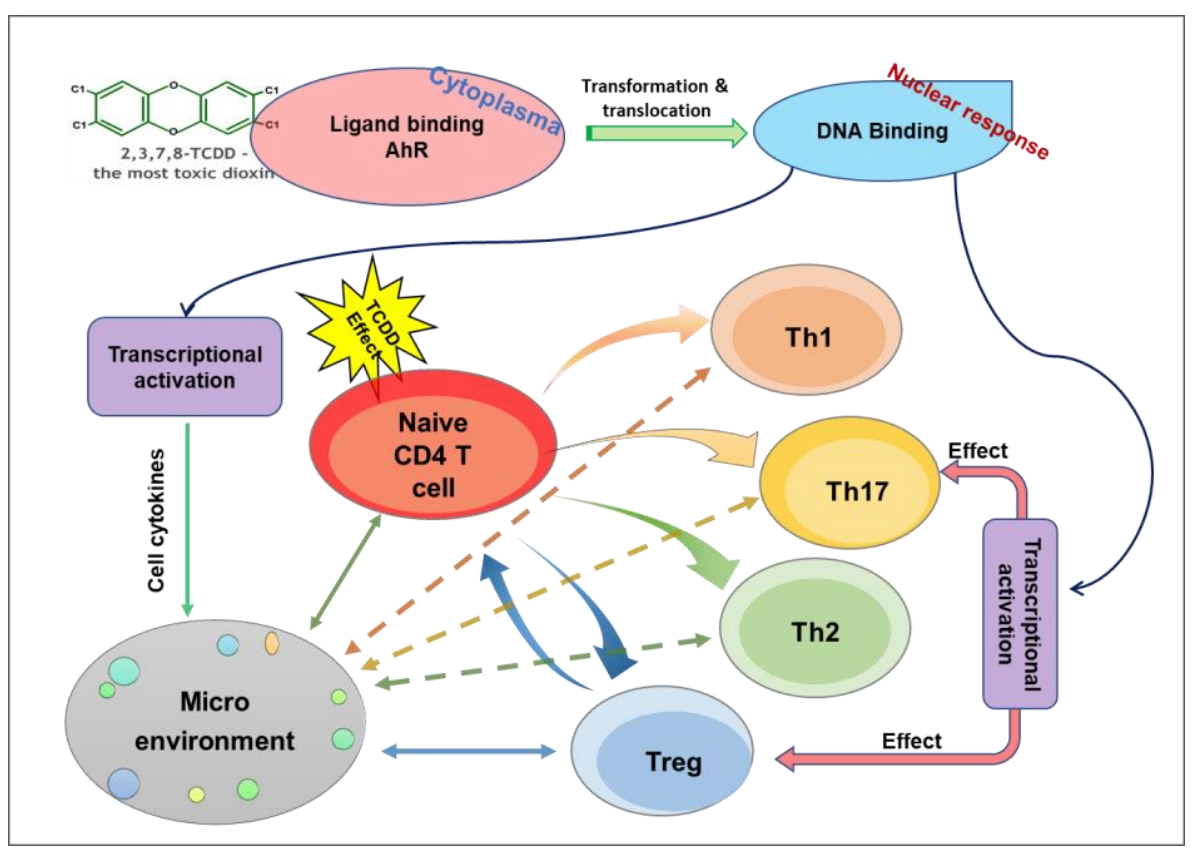

28

29

30

31

32

33

34

35

36

37

38

39

40

41

42

43

44

45

46

47

48

49

50

51

52

53

54

55

56

57

58

59

60

61

62 


\section{Introduction}

2,3,7,8-tetrachloodibenzo-p-dioxin (TCDD), formed as an unintentional by-product of organic synthesis and incomplete combustion ${ }_{2}$ (Sorg, 2013) is the most potent compound among the polychlorinated dibenzo-p-dioxins. TCDD attracted widespread attention in the 1970 's when it was discovered to be a contaminant in the herbicide Agent Orange $_{2}$ and was shown to produce cause birth defects in rodents (York and Mick, 2008). It continues to generate-be a concerns because of its widespread distribution in the environment, persistence in the food chain, and toxicity. Previous studies showed that acute exposure to TCDD results in a variety of human health problems, including immune dysfunction (such as inflammatory autoimmune diseases), neurological pathologies, abnormal development, diabetes, and carcinogenesis (Hankinson, 2005; Luch, 2005).

TCDD can induce a variety of adverse biological and physiological reactions, including immunotoxicity in mammals, e.g., thymus atrophy and suppression of antibody production and cytotoxic T cells activity activation (Kerkvliet, 2002). The mechanisms through which TCDD alters the immune response and promotes immunotoxicity are still not well understood. Many studies have demonstrated that TCDD eould-can impair the immune system, modulate the Th effector cells and other immune cells directly or indirectly through affecting the production of cytokines effrom the immune cells, and finally demonstrate biological immune modulation effects (Chighizola and Meroni, 2012; Quintana, 2013; Tomar and Kerkvliet, 1991). Singh et al. (2008) have showed-shown that TCDD mediates toxicity through activation of the AhR (Singh et al., 2008). The AhR signaling pathway playsed an important role in the course of -modulating bio-the progression of inflammatory autoimmune diseases (Hao and Whitelaw, 2013; Podechard et al., 2008; Veldhoen et al., 2008), especially for Th cell-cell-mediated inflammation (Esser et al., 2009a; Quintana et al., 2008).

The AhR gene has been shown to be highly stable-conserved throughout evolution, which provides evidence of the fundamental importance of AhR in biological systems (Esser et al., 2009b). Current studies show that AhR plays an important role within biological system (; Veldhoen et al., 2008; Lin et al., 2001; Esser et al., 2009b; Quintana et al., 2008). In miceouse, for instance, targeted disruption of the AhR caused an incomplete development of immune organs and an altered immune function (Veldhoen et al., 2008; Lin et al., 2001). More 
recently, experimental and epidemiology studies have shown increasing evidence that the role of AhR in the immune system is particularly related to CD4 helper $\mathrm{T}$ cells $\left(\mathrm{CD} 4^{+} \mathrm{T}\right.$ cells) mediated inflammation (Esser et al., 2009b; Quintana et al., 2008). However, the question whether AhR is essential for the development of a functional immune system is not answered in the literatureknown (Esser et al., 2009a,b; Quintana et al., 2008; Kerkvliet et al., 2002; Gogal et al., 2008).

$\mathrm{CD}^{+} \mathrm{T}$ cells play an integral role in adaptive immune responses. Activation of $\mathrm{CD} 4^{+} \mathrm{T}$ cells needs antigenthe recognize -recognition antigen -in the context of MHC- II molecules (expressed on so-called professional APC such as Macrophage and DC), and then the activated effector $\mathrm{T}$ helper cells produce functional cytokines. Following activation, naïve $\mathrm{CD}^{+} \mathrm{T}$ cells differentiate into one of several lineages of $\mathrm{T}$ helper cells (Th1, Th2, Th17, or Treg), depending primarily on the stimulation factors, the strength of the T Cell Receptor (TCR) signal, and the cytokines present in the surrounding extracellular environment. Differentiation of each $\mathrm{T}$ cell subset is associated with the expression of specific transcription factors $s_{2}$ followed by the secretion of a defined array of cytokines that mediate response to the antigen. Failure to activate an appropriate $\mathrm{T}$ cell response can lead to chronic infection; while exaggerated $\mathrm{T}$ cell responses can cause excessive tissue damage $\overline{\bar{z}}_{\overline{2}}$ and are associated with inflammatory and autoimmune diseases. Th1 and Th17 are the two major functional helper T cell subsets that play an important role in pro-inflammatory and inflammatory autoimmune diseases (Damsker et al., 2010; Solt et al.,2011 Xia et al., 2013).

Exposure to TCDD clearly impairs T cell-dependent immune responses, which contribute to promoting inflammatory autoimmune diseases (Gogal and Holladay, 2008; Holladay et al., 2011). However, it is still difficult to determine whether such immune effects are related to toxicity mediated by ligand-activated AhR signaling, or-could can be attributed to its immune regulation. Among the subsets of T cells, both regulatory Th and effector cells (Th1, Th2, and Th17) can exert either beneficial or pathogenic effects depending on the particular biological settings (Zhu, et al., 2014). The importance of $\mathrm{CD}^{+} \mathrm{CD} 25^{+}$(Treg) in suppressing inflammation has become increasingly clear over the past several years (Josefowicz et al., 2012). Ligand activated AhR can regulate T-cell differentiation, specifically through activation of Treg cells and down-regulation of the pro-inflammatory Th17 cells (Hao and 
Whitelaw, 2013; Singh et al., 2011). To find how TCDD affecteds the immune system, especially the biological effects during the process of Th cells differentiation, we investigated the biological effects of TCDD on differentiation of Th cell subsets in vitro and the potential molecular mechanisms. This study contributes teto the overall understanding of the molecular mechanisms of TCDD induced Th cells differentiation.

\section{Materials and methods}

\subsection{Animals}

Eight to ten-week-old male C57BL/6 mice were purchased from Vital River Laboratories. AhR knockout (Ko) (Chris Bradfield; on C57BL/6J background) mice were purchased from the Jackson Laboratory. All mice were housed in a $12 \_\mathrm{h}$ light/dark cycle and temperature-controlled specific, pathogen-free conditions at the institute for animal experimentation. The AhR knockout mice were genotyped ben PCR. All animal practices were carried out in accordance with the approved guidelines by the Institutional Animal Care and Use Committee (IACUC) of the Institute of Psychology, China Academy of Sciences, China.

\subsection{Antibodies and Other Reagents}

FITC-labeled anti-CD4 (BD Biosciences, \#555346, USA) and PE-labeled anti CD25 (BD Bioscience, \#14-0251-85, USA), PE-labeled anti INF- $\chi_{\mathrm{f}}$ (eBioscience, \#12-1191-82, USA), PE-Cy7-labeled anti-IL4, Alexa 647 labeled anti-IL17 (BD Bioscience, \#560184, USA), Hrizon V450 labeled anti-FoxP3_(BD Bioscience, \#561293, USA), the staining buffer ${ }_{2}$ and $\underline{a}$ transcription factor buffer $\underline{s} S$ et were purchased from BD Bioscience. Carboxyfluorescein diacetate succinimidyl ester (CFSE, \#65-0850, USA) was purchased from eBioscience. The detection of cytokines TGF- $\beta$ (eBioscience, \#BMS614-2, USA) from culture medium was measured by ELISA (eBioscience, USA). ELISA was performed using each specific Ab for the cytokine according to the manufacture's instruction. TCDD (Wellington Laboratories Inc., Canada) dissolved in DMSO (Amresco, USA) was used in the in vitro studies. For cell isolation, magnetic cell sorting methods were used and the corresponding isolation kits were purchased from StemCell Technologies (\#19722, \#18761, USA). Recombinant mouse rIL2 was purchased from PeproTech (\#212-12, Canada). Concanavalin A was purchased from Sigma-Aldrich (\#C0412, USA). A luminescent cell viability assay was used to evaluate the cytotoxicity, and the assay kit was purchased from Promega (\#G7571, USA). 


\subsection{Preparation of spleen lymphocytes and target cell isolation}

The spleen was isolated from C57BL/6 mouse in sterile buffer (1×PBS with 2\% FBS and 1 $\mathrm{mM}$ EDTA, $\mathrm{Ca}^{+} / \mathrm{Mg}^{+}$free) and meshed properly. The cell suspension was filtered through a $70 \mu \mathrm{m}$ nylon cell strainer into a $50 \mathrm{~mL}$ conical tube- and rinsed with up to $20 \mathrm{~mL}$ of the recommended medium. The cells were collected by centrifugation (1500 rpm, $10 \mathrm{~min})$ and re-suspend at in-1-1.5 $\times 10^{8}$ cells $/ \mathrm{mL}$ in the recommended medium. The obtained spleen single cell suspension was used for the Th cell Pre-Enrichment and CD25 positive selection, according to the manufacture's instruction (STEMCELL Technologies Inc, Canada). Cell survival evaluation was determined conducted using conventional trypan blue staining under an optical microscope, and the cell purity was determined by the flow cytometry (BD Calibur). Percoll cell separation media density gradient isolation method was used for the mixed spleen lymphocyte (SLC) isolation ${ }_{2}$ according to the manufacture's protocol (GE Healthcare, \#17-0891-02, USA).

Luminescent cell viability assay based on ATP measurement was used to examine the association of the cytotoxicity of low dose-level TCDD (4 nm, $20 \mathrm{~nm}$, and $40 \mathrm{~nm})$ with differing exposure times (after $24 \mathrm{~h}, 48 \mathrm{~h}$ and $72 \mathrm{~h}$ culture).

\subsection{In vitro cell expansion and culture}

To evaluate the immunosuppressive function of Treg in vitro, the mouse spleen Treg cells were isolated using the magnetic selection system, and the negative fraction, the $\mathrm{CD} 4^{+} \mathrm{CD} 25^{-}$ cell (Tneg) $)_{2}$ was expanded and served as controls in the process. The isolated cells were placed in culture at $2 \times 10^{6}$ cell/1.4 mL/well (12 wells plate) in a modified RPMI1640 medium with $10 \%$ FBS, $100 \mathrm{U} / \mathrm{mL}$ penicillin and streptomycin, $2 \mathrm{mM}$ glutamine, $50 \mu \mathrm{M}$ 2-Mercaptoethanol, $10 \mathrm{mM} \mathrm{HEPES}{ }_{2}$ and $0.5 \mathrm{mM}$ sodium pyruvate. Anti-mouse CD3 and CD28 coated $4 \mu \mathrm{m}$ polystyrene dynabeads (Invitrogen, USA) at 2:1 or 1:1 ratio, and 2000 $\mathrm{U} / \mathrm{mL}$ or $30 \mathrm{U} / \mathrm{mL}$ of recombinant mouse IL-2 (PeproTech, USA) were added for Treg or CD4 Th cell culture in vitro, respectively. To monitor and evaluate the proliferation of target cells, the CFSE was used according to the manufacture's instruction (eBioscience, USA). Negatively isolated mouse spleenic Tneg cells was-were cultured in modified RPMI1640 medium with $4 \mu \mathrm{g} / \mathrm{mL}$ Concanavalin A (Con A). After four days of coculture, cells were harvested and separated with the dynabeads on a magnet and subsequently analyzed for CFSE by flow cytometry. 
cell

Mouse spleen Th cells, the whole mixed spleen lymphocytes, ander isolated mouse spleen Tneg cells wereas cultured with TCDD (T1: $20 \mathrm{nM}, \mathrm{T} 2: 200 \mathrm{nM})_{-}{ }_{2} \theta$ r vehicle ${ }_{2}$ or medium control in the presence of $4 \mu \mathrm{g} / \mathrm{mL}$ Con A, respectively. After 4 days, T cells were collected and washed first with PBS and then with staining buffer-ence respectively. Cell suspension was prepared containing 1 million cells per $150 \mu \mathrm{L}$ staining buffer- and stained with specific surface marker fluorescent antibodies (e.g., antibody for CD3, CD4, CD25) that were added and incubated for 30 minutes at $2-8{ }^{\circ} \mathrm{C}$. Cells were washed one time with $2 \mathrm{ml}$ of staining buffer afterwards and then moved forward to the intracellular staining procedures. Cells were fixed and permeabilized with the transcription factor buffer $\underline{\underline{S} S e t}$ (BD Pharmingen, USA) at $2-8^{\circ} \mathrm{C}$ for 35 minutes $_{2}$ protected from light ${ }_{-}$Tthen the cells were washed two times with perm/wash buffer. After that, cells were intracellularly stained with anti-CD4, IFN- $\chi_{\mp}$, IL17, $\mathrm{IL}_{2}$ and FoxP3 Abs, then measured by flow cytometry. FACS was performed with the Beckman Coulter (Gallios) system. Cells from each group were collected and counted at the end of the experiments.

To evaluate the AhR signaling pathway, spleen $\mathrm{CD}^{+} \mathrm{T}$ cells were isolated from $\mathrm{AhR}$ knockout or littermate control mice and stained with extracellular and intracellular antibodies, then evaluated by flow cytometry as discussed above.

\subsection{Reverse Transcriptase- PCR (RT-PCR)}

Total RNA was prepared by using the RNAqueous-Micro Kit (Life Technologies, \#AM1931, USA), and cDNA were-was synthesized using the Revert Aid First Strand cDNA Synthesis Kkit (Thermo Scientific, \#K1622, USA), according to the manufacturer's instruction. mRNA expression was evaluated by relative quantitative PCR using SYBR Green I Master Mix (\#4707516001, Roche ,Germany) on a LightCycler 480 system (Roche, Germany), according to the manufacturer's instructions. Each assay was performed in triplicate using the cycling condition as follows: $95^{\circ} \mathrm{C}$ for $5 \mathrm{~min}$, followed by 45 cycles of $10 \mathrm{~s}$ at $95^{\circ} \mathrm{C}, 20 \mathrm{~s}$ at $60^{\circ} \mathrm{C}$ and $10 \mathrm{~s}$ at $72^{\circ} \mathrm{C}$. The level of target mRNA, including FoxP3, GATA3, T-bet, and ROR $\gamma \mathrm{t}_{2}$ were estimated by relative quantification-using the typical $\mathrm{Ct}$ method (2- $\Delta \Delta \mathrm{Ct}$ method) by normalizing to GAPDH expression (by-LightCycler® 480 software ${ }_{2}$ (version 1.5, Roche, Germany). The following specific primers were used:

GAPDH forward 5'-CCTCGTCCCGTAGACAAAATG-3';

Reverse 5'-TCTCCACTTTGCCACTGCAA-3'; 


\section{GATA3 primer 5'-AAGCTCAGTATCCGCTGACG-3';}

Reverse 5'-GTTTCCGTAGTAGGACGGGAC-3';

T-bet forward 5'-AGCAAGGACGGCGAATGTT-3';

Reverse 5'-GTGGACATATAAGCGGTTCCC-3';

FoxP3 forward 5'-CCCATCCCCAGGAGTCTTG-3';

Reverse 5'-ACCATGACTAGGGGCACTGTA-3';

ROR $\gamma \mathrm{t}$ - forward 5'- TCCTGCCACCTTGAGTATAGTC -3';

Reverse 5'- GTAAGTTGGCCGTCAGTGCTA -3'.

\subsection{Statistical analysis}

The flow cytometry data were analyzed with the FlowJo software (Tree Star, Inc.). A student's t-test statistical analysis-with SPSS17 was used to analyze cell counts and cell viability, and the value was presented with mean with standard deviation-to cell counts and eell viability. $P<0.05$ indicated a statistically significant difference.

\section{Results}

\subsection{The immunosuppressive function of Treg cells in vitro}

DuringAs the first attempt to expand the Treg cells in vitro, we took advantage of the magnetic selection system, and more than $80 \%$ of the isolated Treg cells were phenotypic $\mathrm{CD} 4^{+} \mathrm{CD} 25^{+}$cells $s_{2}$ according to our flow cytometry analysis (Fig. 1A). In order to functionally test the functions of these cells, we co-cultured Treg cells with Tneg $\left(\mathrm{CD}^{+} \mathrm{CD} 25^{-}\right)$cells for 4 days. The proliferation of Tneg cells was suppressed when mixed with Treg cells (Fig. 1B and C), (Fig. 1B and C)-indicating that the freshly isolated Treg cells were able to suppress the proliferation of the same allogeneic Tneg cells.
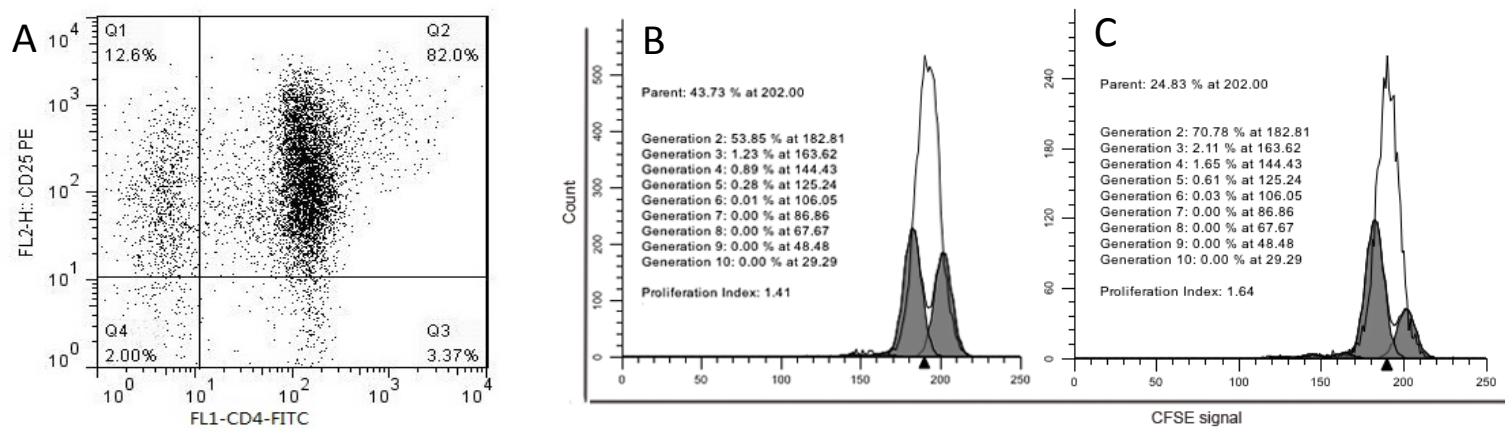

Fig. 1. The immunosuppressive function of Treg cell in vitro. A) Flow cytometry analysis of the purity 
of Treg in the isolated Mouse mouse spleen Treg using the magnetic selection system. B) CFSE labeled $\mathrm{CD}^{+} \mathrm{CD} 25^{-}$Theg and freshly isolated Treg cells. The ratio of undivided parent cell was more than 43\%, which shows showed the potential suppression effect of Treg on Tneg proliferation. C) The proliferation rate of CFSE labeled $C D 4^{+} C D 25^{-}$Tneg without Treg cells.

3.2 The immunoe modulationory effects of TCDD on the differentiation of CD4 helper T cell $\underline{s}$ (Th)

The viability of CD4 helper T cells was found to be not significantly difference-different among from the control group and TCDD treatment groups (at $4 \mathrm{nM}, 20 \mathrm{nM}$, and $40 \mathrm{nM}$ ), however, a decrease of cell viability was found as the time went on in both the lower

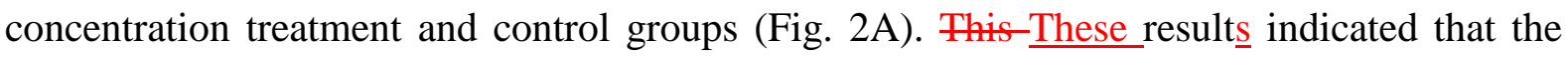
primary CD4 T cell viability was impacted by the environment stimuli which happened toin the culture primary cells. To verify the hypothesis, we added T cell growth factors, e.g., -IL-2 and Concanavalin A (ConA) in the RPMI1640, to further culture primary CD4 T cell for $72 \mathrm{~h}$. Our results showed that the viability of CD $\mathrm{T}$ cell was improved in the new cell culture medium (SI 2. Fig 2).

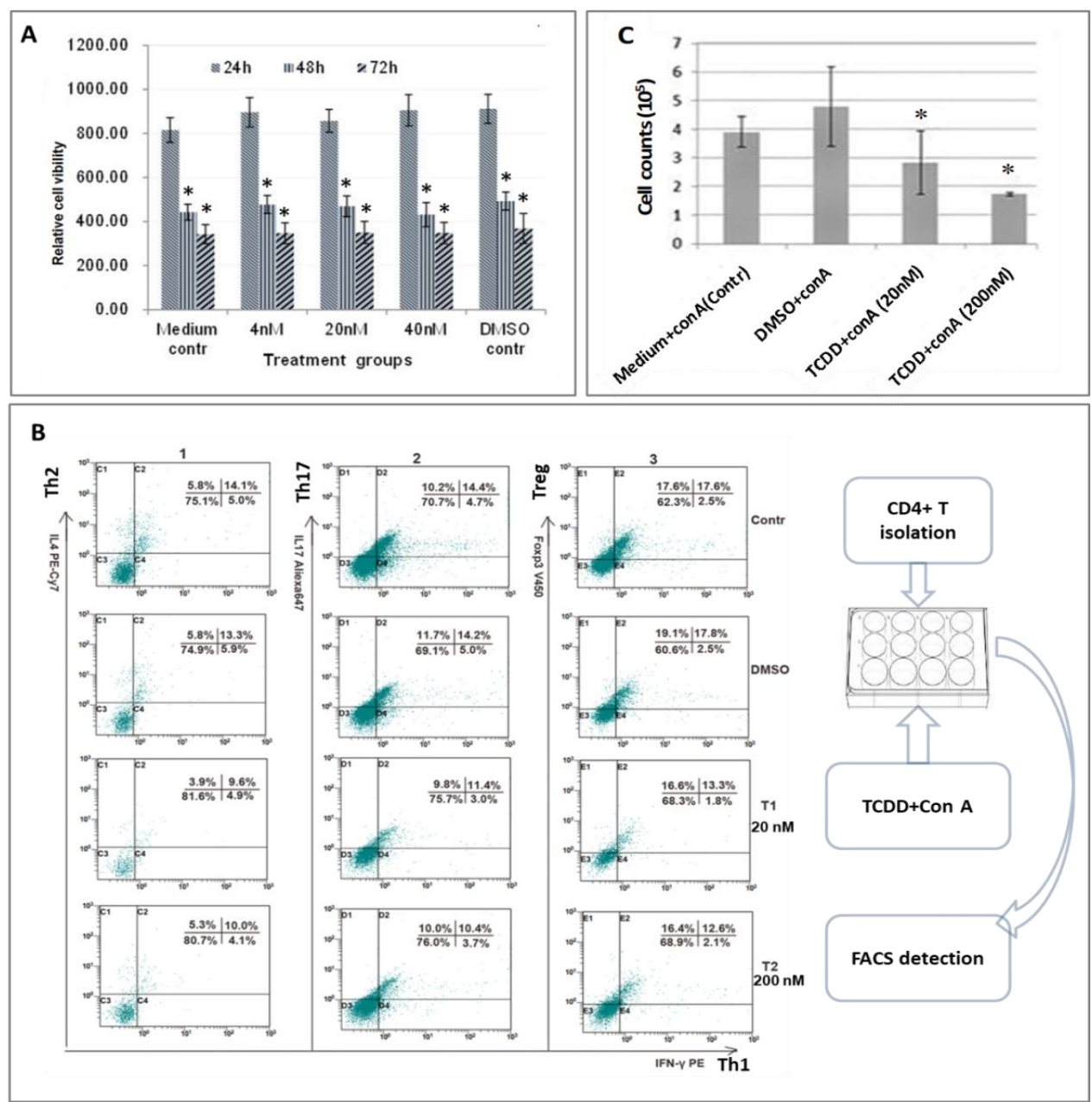


Fig. 2. The immunoe modulationory effects of TCDD on the differentiation of CD4 helper T cell (Th). A) Cell viability of isolated mouse spleen Th cell exposed to TCDD after 3 days. There were no significant differences among groups Auring the courseinitially, however, decreased cell viability was found in every group after 3 days of exposure. B) The effects of TCDD on the differentiation of Th were determined by multicolor flow cytometry after 4 days of exposure. Both the low dose exposure (20 nM) and the high dose exposure (200 nM) down regulated Th1 and Th17. The low dose exposure to TCDD (20 nM) had a significant inmunasuppression-immunosuppressive effect on the inflammatory effector Th cells. C) Cell counts from treatment and control groups at the end of the culture post following treatment with different dose concentrations of TCDD-.

The effects of TCDD on the differentiation of Th cells were determined by multicolor flow cytometry after 4 days of exposure. Both the low and high dose exposure (20 nM and $200 \mathrm{nM}$, respectively) and the high dose exposure $(200 \mathrm{nM})$-down-regulated the structure of the main inflammation effector Th cell subsets, especially Th1 and Th17 cells when compared to the DMSO and medium control. The results also showed that the low dose exposure to TCDD $(20 \mathrm{nM})$ had a significant immunosuppression effect on the differentiation of inflammatory effector Th cells. Though the high dose exposure of TCDD (200 nM) didn't further augment the down-regulation effect on these pro-inflammatory cells, a moderate decrease ing eonstitution of Treg cell was observed after 4 days culture in vitro, compared with the T1 (20 nM) group (Fig. 2B, SI 3. Table 1).

Cell viability analysis also showed the cytotoxicity of TCDD and a dose-response relationship. As shown in Fig. 2C, the high dose-level exposure of TCDD significantly decreased the survival of Th cells after 4 days of culture.

\subsection{The immunoe regulationory effects of TCDD on the whole mixed spleen lymphocytes}

We further investigated the immune regulation effect of TCDD on the whole mixed spleen lymphocytes in SLC culture system. Our results showed that TCDD treatment inhibited the polarization of CD4 $\mathrm{T}$ cell toward to-the pro-inflammation-inflammatory effector Th cell subsets after 4 days when compared to the medium control. At the same time, an apparent dose-response relationship between the TCDD exposure level and the immune suppression effect was found for all the effector Th cells except the Treg cell (Fig. 3A. SI 3. Table 2). There was no dose-response relationship between the total cell survival and the dose level of TCDD exposure (Fig. 3B). In addition, the expression of the characteristic transcription factors of Th1, Th2 and Th17 were not changed significantly after 4 days of TCDD exposure for both the low dose and high dose treatments when compared with the control (Fig. 3C). 
However, we found that the FoxP3 expression was increased over 10 times, which maymight suggest higher proliferation rate of Treg cell in the TCDD treatment groups (Fig. 3C).
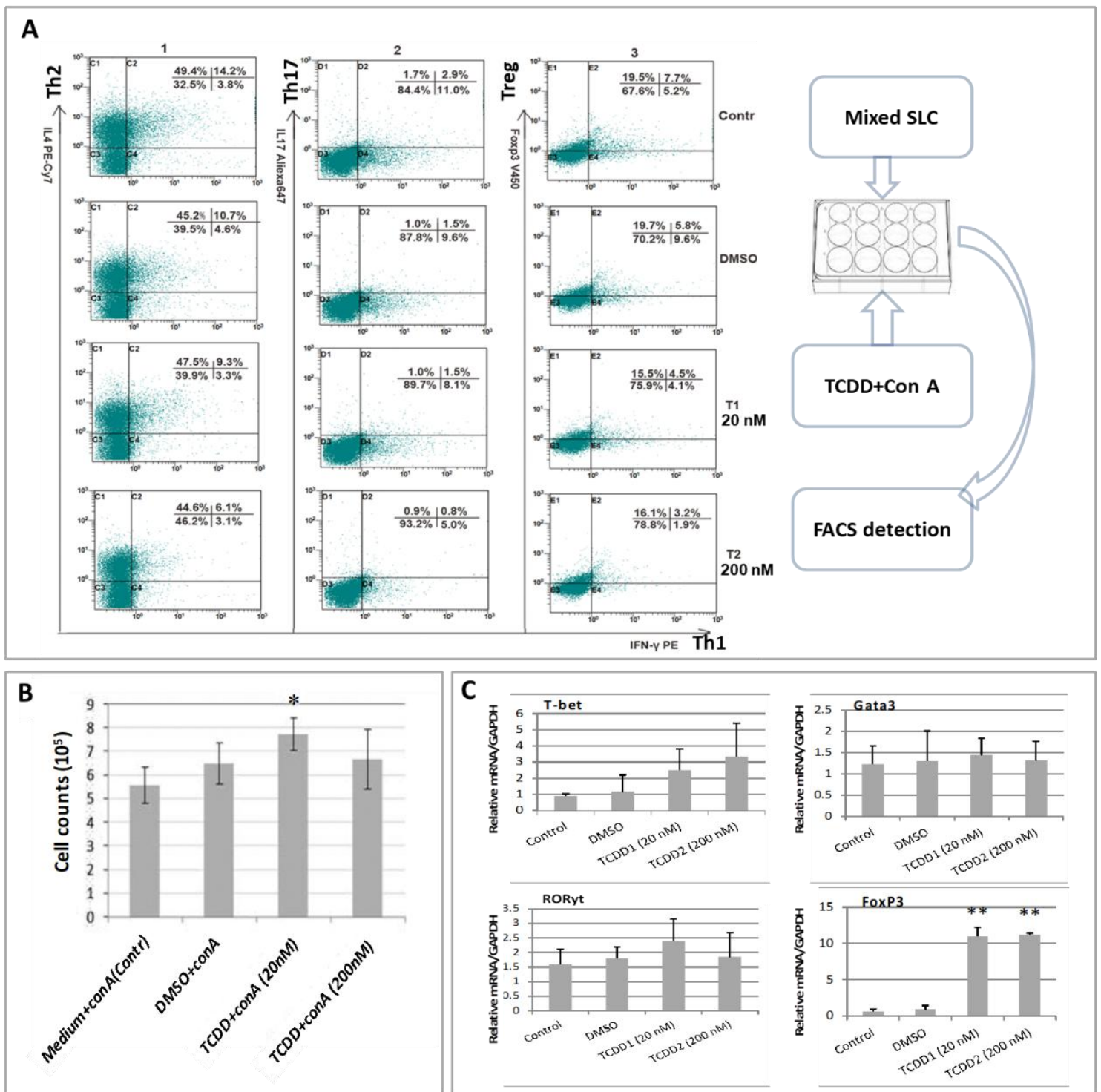

Fig. 3. The immunoe-regulationory effects of TCDD on the whole mixed spleen lymphocyte. A) The effects of TCDD on the differentiation of Th were determined by multicolor flow cytometry after 4 days exposure. Both the low dose TCDD (20 nM) and the high dose (200 nM) exposure decreased differentiation of Th cells in not only the inflammatory Th cell subsets (Th1, Th2, and Th17), but also the Treg cell. B) Cells counts from treatment and control groups at the end of the culture. There was no dose-response relationship between the total cell survival and the dose level of TCDD exposure. $C$ ) The expression of the characteristic transcription factors, T-bet for Th1, GATA3 for Th2, ROR $\mathrm{yt}$ for Th17, and FoxP3 for Treg, in the mixed SLC. The expression of the characteristic transcription factors of Th1, Th2, and Th17 were not changed significantly after 4 days TCDD exposure both for the low dose and high dose treatment group. The FoxP3 expression was increased over 10 times, 
which means-meant the increased proliferation of Treg cell in the TCDD treatment groups.

\subsection{TCDD-mediated immune modulation effects on the differentiation of Tneg cell}

A difference of polarization of CD4 T cell in the Tneg cell culture system was observed, as compared with our previous study of whole CD4 Th cells and mixed SLCs (Fig. 4A). The results showed that low dose exposure of TCDD (20 nM) significantly increased Th1 and Th2 polarization but slightly decreased Th17 polarization (Fig. 4A). The exposure to the high dese level of TCDD also significantly increased the Th1 cell proportion when compared to the control groups. However, compared to the low dose group, the differentiation of Th1 was decreased- wWhile, both the Th2 and Th17 populations were-were both slightly increased in high dose group when compared to that in the low dose groups.

TCDD exposure exhibited a significant induction effect on TGF- $\beta$ production in the mixed SLC culture system, and there was also a dose-response effect (Fig. 4B). However, we didn't find such dose-response effect in the isolated $\mathrm{CD} 4^{+} \mathrm{T}$ lymphocytes. High dose exposure of TCDD (200 nM in the system) attenuated the increase of TGF- $\beta$ levels caused by low dose treatment in isolated $\mathrm{CD}^{+} \mathrm{T}$ lymphocytes (Fig. 4C).
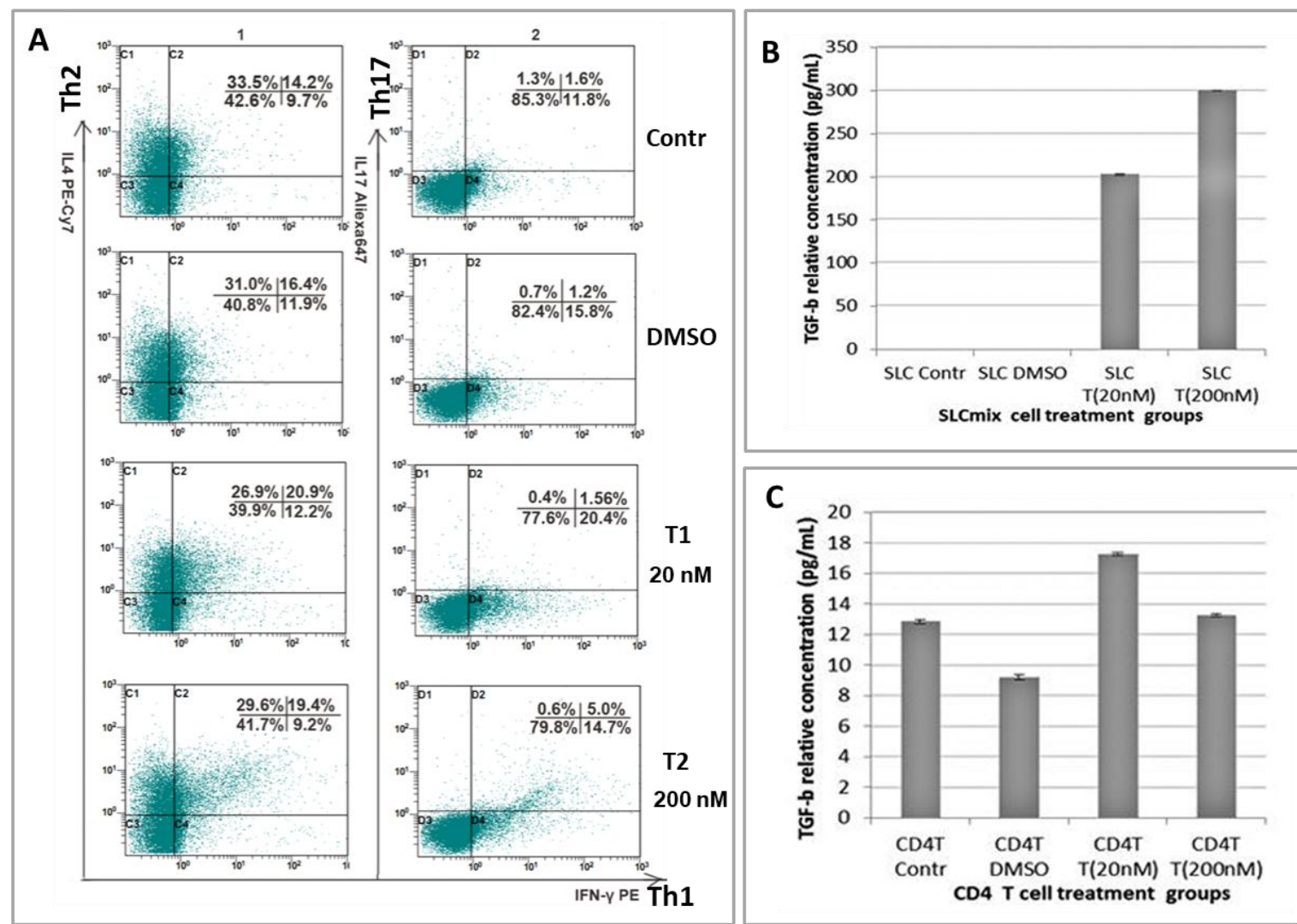

Fig. 4. TCDD-mediated immunoe-modulatoryion effects on the differentiation of Tneg cell. A) TCDD effects on the differentiation of Tneg cells. The low dose exposure of TCDD (20 nM) significantly 

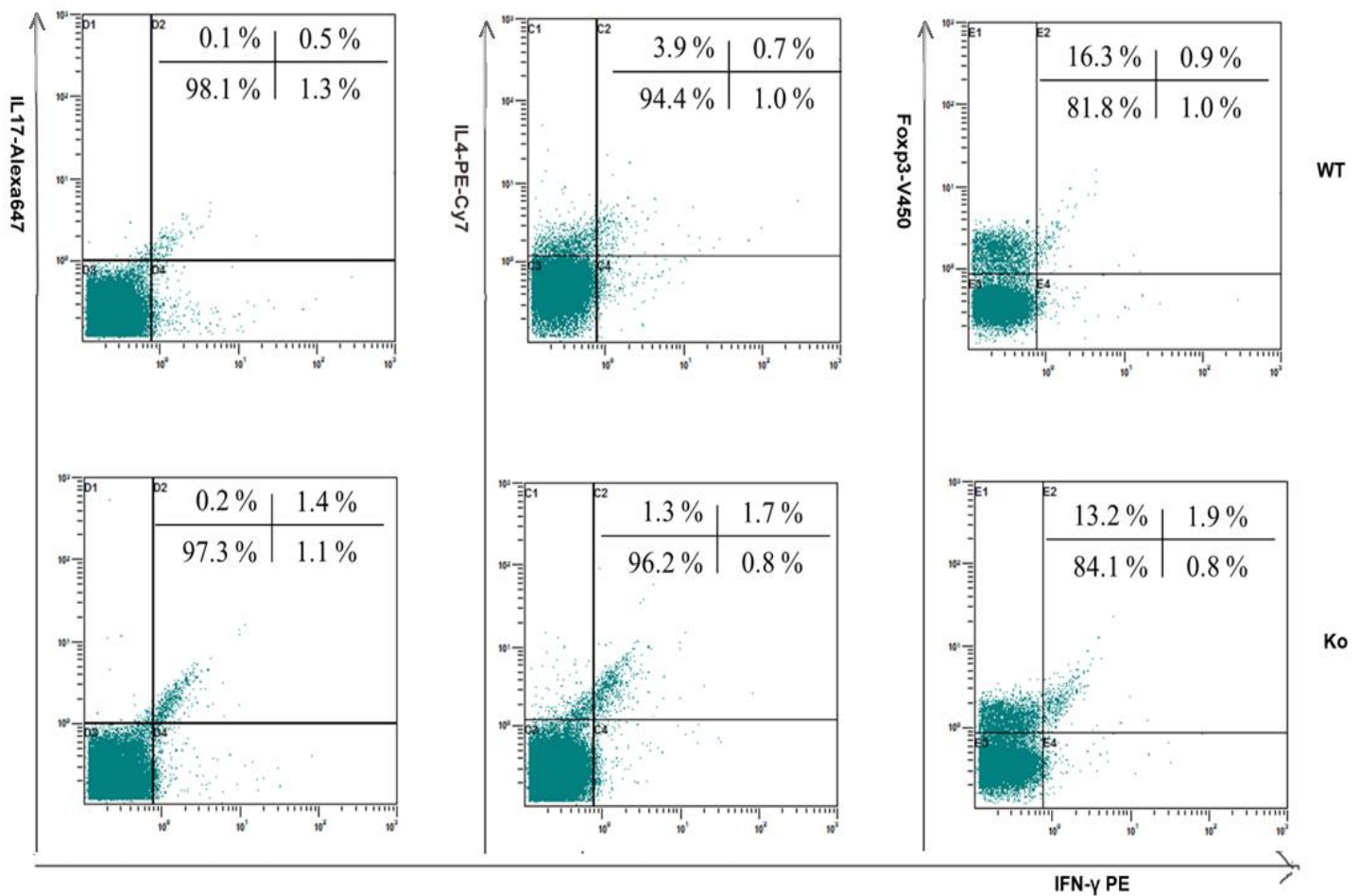

Fig. 5. Evaluation of AhR signaling pathway in modulating the differentiation of $C D 4^{+}$helper $T$ cell subsets differentiation and in the process of immune regulation induced by TCDD. The AhR knockout mice had a significant decrease in the proportion of Th2 cell among the spleen CD4 ${ }^{+}$Th cells, while the proportion of Th17 and Th1 was slightly increased and decreased, respectively, when compared with the littermate wild type control (WT: wild type control, Ko: AhR knockout mice).

It has been shown that the activation of AhR is involved in the differentiation of Th17 cells, which plays an important role in natural immunogenicity (Nguyen et al., 2010; Quintana et al., 2008). Transgenic $A h R$-deficient mouse-mice and its littermate control mouse-(the $A h R^{+/+}$ mice) were used for the $\mathrm{CD}^{+}$Th cell isolation and detection of the constitutional differentiation inef their subsets. The results of flow cytometry demonstrated that the $A h R$ knockout mice had a significant decrease in the proportion of Th2 cell among the spleen $\mathrm{CD} 4^{+}$Th cells, while the proportion of Th17 and Th1 was slightly increased and decreased, 
respectively, when compared with the littermate wild type control. We also found a significant decrease of constitutional differentiation of Treg cells in the AhR knockout mice treatment (Fig. 5. SI 3. Table 3). Thus, in the absence or functional deletion of $A h R$ might significantly impair the differentiation of $\mathrm{CD} 4^{+}$helper T cells.

\section{Discussion}

Previous studies suggested that TCDD had a potential immune suppressive effect, which resulted in decreased inflammatory effector Th cells,-and finally alleviated systemic lupus erythematous (SLE) progression (Li and McMurray, 2009). In our present study, we found that a low dose exposure of TCDD $(20 \mathrm{nM})$ contributed to a decrease in not only the inflammatory effector Th cells including the Th1, Th2 and Th17, but also the Treg cell. However, a high dose level of TCDD (200 nM) does not further affect these cells. On the contrary, high dose exposure of TCDD slightly increased their proportion, except for the Treg cell. Thus, oӨur results thes-suggest that the immmemodulation-immunomodulatory effect of TCDD has a complex and non-linear dose-response relationship. A low dose TCDD contributes 1 to the suppression of immune response, or eontribute to-promotes the immune tolerance to inflammatory autoimmune diseases that are caused by inflammatory effector Th cells. Meanwhile, $\underline{W}$ we also found that the high dose exposure of TCDD (200 nM) further decreases the FoxP3-expressing Treg cell when compared with the low dose (20 nM) treatment. The results suggested that TCDD at high doses more likely targets Treg cell, accelerating the progression of inflammatory autoimmune diseases. Moreover, the high dose exposure of TCDD might increase the susceptibility to exogenous chemicals-induced inflammatory diseases in animals. The cell viability test analysis further confirmed that the cytotoxicity of TCDD may might have a threshold which was not more than $200 \mathrm{nM}$.

The results of TCDD effects on the differentiation of $\mathrm{CD}^{+}$Th cell subsets in the whole mixed SLC culture system showed that both the low dose and the high dose of TCDD exposure decreased the proportion of $\mathrm{CD}^{+}{ }^{+} \mathrm{Th}$ cell, especially for the Th1 and Treg cells, which was similar with the characters ofto what we got in the purified $\mathrm{CD} 4^{+} \mathrm{T}$ cells system above. The gene expression of the characteristic transcription factors of each subset (T-bet for Th1, GATA for Th2, ROR $\gamma$ t for Th17, and FoxP3 for Treg cell) didn't show a significant decrease $_{2}$ except a significant increased expression of FoxP3, which usually suggested an activation of Treg. The gene expression results were not consistent with our immune-phenotyping results. The functional diversity depends on the development stage, the diversity of ligand type or structure, the cell or tissue types involved, the microenvironment 
of the study system, and the dose level of the test articles. Therefore, both the complex interactions mediated by multiple cytokines among the immune cells and the diversity of immune cell in such mixed culture system may contribute to the difference. Considering the important role of AhR signaling pathway in mediating TCDD biological effects, TCDD competition among immune cells within the microenvironment might be an influencing factor for the difference between the immune-phenotyping results and gene expression. Our results indicate the essential role of $\mathrm{AhR}$ for the development of a functional immune system is inconsistent with the activation or suppression of AhR leading to profound immunosuppression (Esser, 2009; Esser et al., 2009; Gogal and Holladay, 2008; Kerkvliet, 2012; Quintana et al., 2008; Quintana et al., 2010).

Our results show that the low dose TCDD exposure significantly increased the Th1, while decreaseinge the proportion of $\mathrm{Th} 2$ and Th17 subsets. Inflammation or autoimmune diseases mediated by Th1 might be dominant in a circumstance of functional deletion of Treg cell. The relative high dose TCDD exposure, however, decreased the proportion of Th1, while increaseingd the proportion of Th2 and Th17 cells. These results suggested a more frequent conversion among different cell subsets. Peripheral immune tolerance and homeostasis are dynamically maintained by functional differentiation within the FoxP3-expressing population, the occasional conversion between Treg and non-Treg cells, and the interactions among them. The absence of Treg cells contributed to a decrease in Th cells sensitivity to TCDD induced immune suppression effects. Treg cells play_ans important role not only in the immune regulation $_{2}$ but also in cytotoxicity processes induced by TCDD with-in a dose-dependent manner. TGF- $\beta$ has functions in the immunoe-regulation, proliferation, differentiation, and the development and immune regulatery of Treg cell (Chen et al., 2003; Fantini et al., 2006). TCDD showed different impacts on the TGF- $\beta$ production in the two different test systems (the mixed SLC and the purified spleen CD4 Th cells). The TGF- $\beta$ content and the proportion of Treg cell were inconsistent in each respective test system. Further studies on the role of potent immune cytokines are necessary.

Our investigation of the structure of Th cell subsets of $A h R$-deficient mice demonstrated a difference from the wild type control. Moreover, considering the important biological-role of AhR signaling in mediating the biological effects of dioxin-like materials (Benson and Shepherd, 2011; Kerkvliet, 2012; Quintana, 2013), we showed that the AhR signaling pathway played an important role in modulating the CD4 Th cell subsets constitutional differentiation. AhR might be required in the process of different immune modulation effect 
induced by TCDD. Previous in-vivo studies have showed that TCDD treatment activated-AhR signaling pathways affect the immune response, ${ }_{2}$ especially that mediated by the CD4 Th cell subsets, either through either inducing differentiation of functional Treg cells, while inhibiting the differentiation of Th17 cell at the same time (Quintana et al., 2008), or decreasing the proinflammatory cytokines levels (such as IL6, IL-12,IFN-r and TNF-a) and inducing the differentiation of Treg cell (Benson and Shepherd, 2011). These processes; together contributed to suppressed experimental autoimmune diseases in a mouse model. The results showed that TCDD triggered the conversion of approximately 13\% of the CD4 Th cells in culture CD4 Treg cells, which showed-suggested a suppressive activity similar to that of Treg cells induced in vitro with TGF- $\beta$ or natural CD4 Treg cells isolated from mice (Quintana et al., 2008). This-These findings provided a new insight into immune effects and potential mechanisms involved withef dioxin-like materials.

\section{Conclusions}

Our study provides an evidence that TCDD affects CD4 Th cell-mediated immune homeostasis with strong dependency on dose and microenvironment. Exposure to the low doses of TCDD contributes to decreased proportions of inflammatory effector Th cells, while the high dose exposure lead to decreased proportions of Treg cells, which may promote an aberrant immune response. The absence of Treg cells decreases the immune regulation effects but increases the immune toxicity effects. Moreover, our study suggests that TCDD affects Th cell subsets differentiation and maturation processes in purified splenic CD4 cells as well as in mixed SLC. Our findings contribute to the understanding of how TCDD impacts immune modulation and immune toxicity, which is the key for the development and clinical application of therapeutic agents.

\section{Conflict of interest}

The authors declare no conflict of interest.

\section{Acknowledgements}

This work was supported in parts by the National Natural Science Foundation of China (grant number 21277168, 21525730, 21836004), the Strategic Priority Research Program of the Chinese Academy of Sciences (No. XDB14030401, XDB14030402), the Sanming Project of Medicine in Shenzhen (SZSM201811070), the National Natural Science Foundation of China Award (Grant No. 21407162. 2014), and the European Union's Seventh Framework Programme and Horizon 2020 Research and Innovation Programme under Marie Sklodowska-Curie Actions grant no. 713683 (H2020) (The H.C. Ørsted Postdoc programme, 

Guo at HGG Research LLC for editing this manuscript.

\section{References}

Benson, J.M., Shepherd, D.M., 2011. Aryl Hydrocarbon Receptor Activation by TCDD Reduces Inflammation Associated with Crohn's Disease. Toxicol Sci 120, 68-78.

Chen, W., Jin, W., Hardegen, N., Lei, K.J., Li, L., Marinos, N., McGrady, G., Wahl, S.M., 2003. Conversion of peripheral CD4+CD25- naive $\mathrm{T}$ cells to CD4+CD25+ regulatory $\mathrm{T}$ cells by TGF- $\beta$ eta induction of transcription factor FoxP3. J Exp Med 198, 1875-1886.

Chighizola, C., Meroni, P.L., 2012., The role of environmental estrogens and autoimmunity. Autoimmun Rev 11, A493-A501.

Damsker, J. M., Hansen, A. M., Caspi, R. R., 2010. Th1 and Th17 cells Adversaries and collaborators. Ann Ny Acad Sci 1183, 211-221.

Esser, C., 2009a. The immune phenotype of AhR null mouse mutants: Not a simple mirror of xenobiotic receptor over-activation. Biochem Pharmacol 77, 597-607.

Esser, C., Rannug, A., Stockinger, B., 2009b. The aryl hydrocarbon receptor in immunity. Trends Immunol 30, 447-454.

Fantini, M.C., Becker, C., Tubbe, I., Nikolaev, A., Lehr, H.A., Galle, P., Neurath, M.F., 2006. Transforming growth factor beta induced FoxP3+ regulatory $\mathrm{T}$ cells suppress Th1 mediated experimental colitis. Gut 55, 671-680.

Godfrey, W.R., Ge, Y.G., Spoden, D.J., Levine, B.L., June, C.H., Blazar, B.R., Porter, S.B., 2004. In vitro-expanded human CD4(+)CD25(+) T-regulatory cells can markedly inhibit allogeneic dendritic cell-stimulated MLR cultures. Blood 104, 453-461.

Gogal, R.M., Jr., Holladay, S.D., 2008. Perinatal TCDD exposure and the adult onset of autoimmune disease. J Immunotoxicol 5, 413-418.

Hankinson, O., 2005. Role of coactivators in transcriptional activation by the aryl hydrocarbon receptor. Arch Biochem and Biophys 433, 379-386.

Hao, N., Whitelaw, M.L., 2013. The emerging roles of AhR in physiology and immunity. Biochem Pharmacol 86, 561-570.

Holladay, S.D., Mustafa, A., Gogal, R.M., Jr., 2011. Prenatal TCDD in mice increases adult autoimmunity. Reprod Toxicol 31, 312-318.

Josefowicz, S.Z., Lu, L.F., Rudensky, A.Y., 2012. Regulatory T Cells: Mechanisms of Differentiation and Function. Annu Rev Immunol 30, 531-564.

Kerkvliet, N.I., 2002. Recent advances in understanding the mechanisms of TCDD immunotoxicity. Int Immunopharmacol 2, 277-291.

Kerkvliet, N.I., 2012. TCDD: an environmental immunotoxicant reveals a novel pathway of immunoregulation--a 30-year odyssey. Toxicol Pathol 40, 138-142.

Li, J., McMurray, R.W., 2009. Effects of chronic exposure to DDT and TCDD on disease activity in murine systemic lupus erythematosus. Lupus 18, 941-949. 
Lin, T. M., Ko, K., Moore, R. W., Buchanan, D. L., Cooke, P. S., Peterson, R. E., 2001. Role of the aryl hydrocarbon receptor in the development of control and 2,3,7,8-tetrachlorodibenzo-p-dioxin-exposed male mice. J Toxicol Env Heal A 64, (4), 327-342.

Luch, A., 2005. Chemicals as tumor-inducing agents. Discov Med 5, 472-477.

Nguyen, N.T., Kimura, A., Nakahama, T., Chinen, I., Masuda, K., Nohara, K., Fujii-Kuriyama, Y., Kishimoto, T., 2010. Aryl hydrocarbon receptor negatively regulates dendritic cell immunogenicity via a kynurenine-dependent mechanism. Proc Nati Acad Sci USA 107, 19961-19966.

Podechard, N., Lecureur, V., Le Ferrec, E., Guenon, I., Sparfel, L., Gilot, D., Gordon, J.R., Lagente, V., Fardel, O., 2008. Interleukin-8 induction by the environmental contaminant benzo(a)pyrene is aryl hydrocarbon receptor-dependent and leads to lung inflammation. Toxicol Let 177, 130-137.

Quintana, F.J., 2013. The aryl hydrocarbon receptor: a molecular pathway for the environmental control of the immune response. Immunology 138, 183-189.

Quintana, F.J., Basso, A.S., Iglesias, A.H., Korn, T., Farez, M.F., Bettelli, E., Caccamo, M., Oukka, M., Weiner, H.L., 2008. Control of T-reg and TH17 cell differentiation by the aryl hydrocarbon receptor. Nature 453, 65 .

Quintana, F.J., Murugaiyan, G., Farez, M.F., Mitsdoerffer, M., Tukpah, A.M., Burns, E.J., Weiner, H.L., 2010. An endogenous aryl hydrocarbon receptor ligand acts on dendritic cells and $\mathrm{T}$ cells to suppress experimental autoimmune encephalomyelitis. Proc Nati Acad Sci USA 107, 20768-20773.

Quintana, F.J., Sherr, D.H., 2013. Aryl hydrocarbon receptor control of adaptive immunity. Pharmacol Rev 65, 1148-1161.

Singh, N.P., Nagarkatti, M., Nagarkatti, P., 2008. Primary peripheral T cells become susceptible to 2,3,7,8-tetrachlorodibenzo-p-dioxin-mediated apoptosis in vitro upon activation and in the presence of dendritic cells. Mol Pharmacol 73, 1722-1735.

Singh, N.P., Singh, U.P., Singh, B., Price, R.L., Nagarkatti, M., Nagarkatti, P.S., 2011. Activation of Aryl Hydrocarbon Receptor (AhR) Leads to Reciprocal Epigenetic Regulation of FoxP3 and IL-17 Expression and Amelioration of Experimental Colitis. Plos One 6.

Sorg, O., 2013. AhR signalling and dioxin toxicity. Toxicol Lett 230(2)

Solt, L. A., Kumar, N., Nuhant, P., Wang, Y. J., Lauer, J. L., Liu, J., Istrate, M. A., Kamenecka, T. M., Roush, W. R., Vidovic, D., Schurer, S. C., Xu, J. H., Wagoner, G., Drew, P. D., Griffin, P. R., Burris, T. P., 2011. Suppression of T(H)17 differentiation and autoimmunity by a synthetic ROR ligand. Nature472, (7344), 491-U547.

Sun, Y.V., Boverhof, D.R., Burgoon, L.D., Fielden, M.R., Zacharewski, T.R., 2004. Comparative analysis of dioxin response elements in human, mouse and rat genomic sequences. Nucleic Acids Res $32,4512-4523$.

Tomar, R.S., Kerkvliet, N.I., 1991. Reduced T-helper cell function in mice exposed to 2, 3, 7, 8-tetrachlorodibenzo-p-dioxin(TCDD). Toxicol Let 57, 55-64.

Veldhoen, M., Hirota, K., Westendorf, A.M., Buer, J., Dumoutier, L., Renauld, J.C., Stockinger, B., 2008. The aryl hydrocarbon receptor links $\mathrm{T}(\mathrm{H}) 17$-cell-mediated autoimmunity to environmental toxins. Nature 453, 106. 
Xia, M., Liu, J.; Wu, X., Liu, S., Li, G., Han, C., Song, L., Li, Z.; Wang, Q., Wang, J., Xu, T., Cao, X., 2013. Histone methyltransferase Ash1l suppresses interleukin-6 production and inflammatory autoimmune diseases by inducing the ubiquitin-editing enzyme A20. Immunity 39, (3), 470-81.

York, G., Mick, H., 2008. Last Ghost of the Vietnam War. The Globe and Mail. Toronto, ON Canada: Phillip Crawley.

Zhu, C., Xie, Q., Zhao, B., 2014. The Role of AhR in Autoimmune Regulation and Its Potential as a Therapeutic Target against CD4 T Cell Mediated Inflammatory Disorder. Int J Mol Sci 15, 10116-10135. 


(1)

